\title{
Global migration in the twentieth and twenty-first centuries: the unstoppable force of demography
}

\section{Thu Hien Dao ${ }^{1,2} \cdot$ Frédéric Docquier ${ }^{3} \cdot$ Mathilde Maurel $^{4,5,6} \cdot$ Pierre Schaus $^{7}$}

Accepted: 29 October 2020 / Published online: 13 January 2021

(c) Kiel Institute 2021

\begin{abstract}
This paper sheds light on the global migration patterns of the past 40 years, and produces migration projections for the 21 st century. To do this, we build a simple model of the world economy, and we parameterize it to match the economic and sociodemographic characteristics of the world in the year 2010. We conduct backcasting and nowcasting exercises, which demonstrate that our model fits very well the past and ongoing trends in international migration, and that historical trends were mostly governed by demographic changes. Then, we describe a set of migration projections for the 21st century. In line with the backcasts, our world migration prospects are mainly governed by socio-demographic changes. Using immigration restrictions or development policies to curb these pressures requires sealing borders or triggering unprecedented economic takeoffs in migrants' countries of origin. Increasing migration is thus a likely phenomenon for the 21 st century.
\end{abstract}

Keywords International migration · Migration prospects · World economy · Inequality

\footnotetext{
We thank three anonymous referees for their helpful comments and suggestions. We also benefited from discussions with Christiane Clemens, Giuseppe de Arcangelis, Timothy Hatton, Vincent Vanderberghe, and Gerald Willmann. This paper was presented at the conference on "Demographic Challenges in Africa" jointly organized by the French Agency for Development and the University of Paris 1 Panthéon-Sorbonne in February 2017, at the 8th International Conference on "Economics of Global Interactions: New Perspectives on Trade, Factor Mobility and Development" at the University of Bari Aldo Moro in September 2017, and at the Workshop on "The drivers and impacts of migration and labour mobility in origins and destinations: Building the evidence base for policies that promote safe, orderly and regular people's and labour mobility for poverty reduction and sustainable development" at FAO Headquarters in Rome in December 2017. The authors are grateful to the participants for valuable comments. Thu Hien Dao acknowledges financial support from the European Commission in the framework of the European Doctorate in Economics Erasmus Mundus (EDEEM). Frédéric Docquier and Pierre Schaus acknowledge financial support from the ARC convention on "New approaches to understanding and modelling global migration trends" (convention 18/23-091).
}

Electronic supplementary material The online version of this article (https://doi.org/10.1007/s 1029 0-020-00402-1) contains supplementary material, which is available to authorized users.

Extended author information available on the last page of the article 
JEL classification $\mathrm{F} 22 \cdot \mathrm{F} 24 \cdot \mathrm{J} 11 \cdot \mathrm{J} 61 \cdot \mathrm{O} 15$

\section{Introduction}

Between 1960 and 2019, the worldwide stock of international migrants increased from 92 to 270 million, almost at the same pace as the world population. The worldwide share of migrants has fluctuated around 3\% until 2010 (Ozden et al. 2011), with a rise since then until reaching $3.5 \%$ in 2019. In contrast, the foreign-born population increased more rapidly than the total population in high-income countries (HIC), boosting the average proportion of foreigners from 4.5 to $12.0 \%(+7.5$ percentage points). A remarkable fact is that this change is mostly explained by the inflow of immigrants from less developed countries (LDC). The underlying root causes of this trend are known (population growth disparities between rich and poor countries, economic inequality, increased globalization, political instability, etc.). However, quantitatively speaking, little is known about their relative importance, and about the changing educational structure of past migration flows. Furthermore, the very same root causes are all projected to exert a strong influence on migration in the coming decades, while little is known about the predictability of future migration flows. This paper sheds light on these issues, addressing key questions such as: How have past income disparities, educational changes and population growth differentials shaped past migration flows? What are the pairs of countries responsible for large variations in low-skilled and high-skilled migration? How many potential migrants can be expected for the 21st century? How will future changes in education and productivity affect migration flows in general, and migration pressures to HIC in particular? Can development or visa policies be implemented to limit these flows?

To address these issues, we develop a simple and abstract model of the world economy that highlights the major mechanisms underlying migration decisions and wage inequality in the long term. It builds on a migration technology and a production technology, uses consensus specifications, and includes a limited number of parameters that can be calibrated to match the economic and socio-demographic characteristics of the world in the year 2010. Then, we conduct a set of backcasting and nowcasting experiments, which consists in simulating bilateral migration stocks retrospectively or for very recent years, and in comparing the backcasts and nowcasts with observed migration stocks. We show that our backcasts and nowcasts fit very well the observed migration data. This suggests that our model can be used to identify the main sources of variation and to predict long-run migration trends.

Analyzing counterfactual historical trends with constant distributions of income, education level or population, we highlight the key role of demography. In LDCs, the total stock of emigrants increased almost at the same pace as the total population, leading to small fluctuations of the average emigration rate between 2.6 and $3.0 \%$. As part of this emigration process, the average propensity to emigrate from LDCs to HICs has increased by less than one percentage point over half a century. These changes have been governed by several factors (such as conflicts, rising income disparities, rising education level, or changing migration costs). They are too small to explain the threefold increase in immigration experienced in the North. 
Population growth differential is the main factor that reconciles stable emigration patterns in LDCs with "explosive" immigration patterns in HICs. Over the last 50 years, population growth has been systematically greater in developing countries. ${ }^{1}$ Our numerical experiments confirm that most of the historical changes in international migration are explained by population growth differentials between countries. In particular, the world migration stocks would have virtually been constant if the population size of developing countries had not changed. Importantly, this does not mean that convergence in income and education does not matter (as apparent from our forecasting experiments). It simply means that convergence has been way to small to counteract the effect of demography, whatever the calibration of the technology and the size of human capital externalities.

We then feed our calibrated model with exogenous socio-demographic scenarios, and produce micro-founded projections of migration stocks by education level for the 21 st century. We are aware that the future of migration can be influenced by many unforeseeable factors (e.g., emergence of new attractive immigration centers, economic and demographic effects of global pandemics, geopolitical cataclysms, etc.). For example, only time will tell whether the current Covid-19 pandemic will transform migration dynamics and in which direction. Hence, the objective is not to predict future migration but to identify how the traditional root drivers of migration will affect migration trends all other things being equal.

In line with the backcasting exercise, we find that the future trends in international migration are mostly governed by socio-demographic changes (i.e., changes in population size and in educational attainment). Focusing on OECD member states, we foresee a highly robust increase in their proportion of immigrants. The magnitude of the change is highly insensitive to the technological environment, and to the education scenario. In particular, a rise in schooling in developing countries increases the average propensity to emigrate but also reduces population growth rates; as far as migrant stocks are concerned, these effects are balancing each other. Changes in educational attainment strongly affect the skill composition of future migration flows but have little effect on their size. Overall, under constant immigration policies, the average share of immigrants in OECD countries increases from 12 to $25-28 \%$ during the 21 st century. Given their magnitude, expected changes in immigration are henceforth referred to as migration pressures, although we do not make any value judgments about their desirability or about their welfare effects within the sending and receiving countries. This surge is mostly due to rising migration flows from sub-Saharan Africa, from the Middle East, and from a few Asian countries. Expected immigration pressures are greater in European countries $(+21.2$ percentage points) than in the United States $(+14.3$ percentage points). The greatest variations in immigration rates are observed in the United Kingdom, France, Spain; Canada is also strongly affected.

\footnotetext{
1 The population ratio between LDCs and HICs increased from 3.1 in 1960 to 5.5 in 2010. This explains why a $0.9 \%$ increase in emigration rate from LDCs translated into a $6.5 \%$ increase in the share of immigrants to HICs.
} 
Curbing such migration pressures is difficult. Sealed borders are virtually needed to keep future migration stocks at their current level. Such drastic restrictive policies are unlikely to be implementable if the basic right to family reunification is respected. Turning our attention to development policies, we show that keeping their total emigration stock constant requires triggering unprecedented economic takeoffs.

Our paper speaks to the literature on long-term migration forces. The interdependencies between migration, population and income have rarely been accounted for in projection exercises. The demographic projections of the United Nations do not anticipate the economic and demographic forces that shape migration flows. ${ }^{2}$ The Wittgenstein projections rely on a more complex methodology that consists of a set of probabilities to emigrate (or to immigrate) multiplied by the native population levels in the origin countries but imperfectly account for interdependencies between migration and economic variables (Lutz et al. 2017). ${ }^{3}$ Hatton and Williamson (2003) examine the determinants of net emigration from Africa using a panel of 21 countries between 1977 and 1995, then subsequently use the regression estimates to predict an intensification of migration from Africa by the year 2025. From the receiving countries' perspective, Hatton and Williamson (2011) identify the various drivers of emigration rates from developing countries to the United States from 1970 to 2004, and find abating signs of migration from Latin America and Asia to the United States while rising trend will continue in Africa. Hanson and McIntosh (2016) use empirical regressions to establish a link between changes in the demographic size/ structure at origin and emigration flows. Ignoring changes in education levels and considering an exogenous economic environment, they show that the African migration pressures will mostly affect European countries until the mid-21st century.

The common feature of the present study is the use of past observations and exogenous demographic forecasts to project future migration. Our contribution is threefold. First, in terms of modeling, our paper builds on a general equilibrium framework which accounts for the interactions between migration decisions, productivity and wage disparities. Our migration projections are demographically and economically rooted. They result from a micro-founded migration technology and are compatible with the endogenous evolution of income disparities. Second, the use of a random utility specification allows allocating the world labor across multiple corridors as a function of the relative attractiveness of all destinations. Third, in terms of country coverage, our world-economy model includes the majority of countries in the world (i.e., 180 countries). The simulation results therefore offer a better overview of future global migration, although we acknowledge that migrant concentrate in a small number of corridors. ${ }^{4}$

\footnotetext{
2 In the medium variant, they assume long-run convergence towards low fertility and high life expectancy across countries, and constant immigration flows.

${ }^{3}$ Future migration flows reflect expert opinion about future socio-political and economic trends that could affect migration. From 2060 onwards, it is assumed that net migration flows converge to zero (attained in the 2095-2100 period), implying that migration stocks also converge to zero.

4 A similar approach is used in Docquier and Machado (2017) who focus on 34 destination countries and consider non-official socio-demographic projections. Identifying assumptions are refined here thanks to the backcasting experiments, and richer technology and policy variants are considered.
} 
The remainder of the paper is organized as follows. Section 2 describes the model, defines its competitive equilibrium, and discusses its parameterization. Section 3 presents the results of the backcasting and nowcasting exercises. Forecasts are then provided in Sect. 4. Finally, Sect. 5 concludes.

\section{Model}

The model depicts an abstract economy with two classes of workers and $J$ countries $(j=1, \ldots, J)$. The skill type $s$ is equal to $h$ for college graduates, and to $l$ for the less educated. We first describe the migration technology, which determines the condition under which migration to a destination country $j$ is profitable for type- $s$ workers born in country $i$. We then describe the production technology, which determines wage disparities. The combination of endogenous migration decisions and equilibrium wages jointly determines the world distribution of income and the allocation of the world population. Finally, we discuss some important simplifying assumptions of the model and explain how we calibrate it to match migration, economic and socio-demographic data for the year 2010.

Migration technology At each period $t$, the number of working age natives of type $s$ and originating from country $i$ is denoted by $N_{i, s, t}$. Each native decides whether to emigrate to another country or to stay in their home country; the number of migrants from $i$ to $j$ is denoted by $M_{i j, s, t}$ (hence, $M_{i i, s, t}$ represents the number of non-migrants). After migration, the resident labor force of type $s$ in country $j$ is given by $L_{j, s, t}$.

Individual decisions to emigrate result from the comparison of discrete alternatives. To model them, we use a standard Random Utility Model (RUM) with a deterministic and a random component. The deterministic component is assumed to be logarithmic in income and to include an exogenous dyadic component. ${ }^{5}$ At time $t$, the utility of a type- $s$ individual born in country $i$ and living in country $j$ is given by:

$$
u_{i j, s, t}=\tilde{\gamma} \ln w_{j, s, t}+\ln v_{i j, s, t}+\xi_{i j, s, t},
$$

where $w_{j, s, t}$ denotes the wage rate attainable in the destination country $j ; \tilde{\gamma}$ is a parameter governing the marginal utility of income; $v_{i j, s, t}$ stands for the non-wage income and amenities in country $j$ (public goods, non-monetary amenities, and transfers minus taxes) and is netted from the legal and private costs of moving from $i$ to $j ; \xi_{i j, s, t}$ is the random taste component capturing heterogeneity in the preferences for alternative locations, in mobility costs, in assimilation costs, etc. This random component guarantees that individuals make heterogeneous location decisions, and cross-migration flows are possible.

\footnotetext{
5 Although Grogger and Hanson (2011) find that a linear utility specification fits the patterns of positive selection and sorting in the migration data well, most studies rely on a logarithmic utility function (Bertoli and Moraga Fernandez-Huertas 2013; Beine and Parsons 2015; Beine et al. 2019; Ortega and Peri 2013).
} 
The utility obtained when the same individual stays in his origin country is given by:

$$
u_{i i, s, t}=\tilde{\gamma} \ln w_{i, s, t}+\ln v_{i i, s, t}+\xi_{i i, s, t} .
$$

The random term $\xi_{i j, s, t}$ is assumed to follow an iid extreme-value distribution of type I with scale parameter $\mu .{ }^{6}$ Under this hypothesis, the probability that a type-s individual born in country $i$ moving to country $j$ is given by the following logit expression (McFadden 1984):

$$
\frac{M_{i j, s, t}}{N_{i, s, t}}=\operatorname{Pr}\left[u_{i j, s, t}=\max _{k} u_{i k, s, t}\right]=\frac{\exp \left(\frac{\tilde{\gamma} \ln w_{j, s, t}+\ln v_{i j, s, t}}{\mu}\right)}{\sum_{k} \exp \left(\frac{\tilde{\gamma} \ln w_{k, s, t}+\ln v_{i k, s, t}}{\mu}\right)} .
$$

Hence, the emigration rate from $i$ to $j$ depends on the characteristics of all potential destinations $k$. The staying rates $\left(\frac{M_{i, s, t}}{N_{i, s, t}}\right)$ are governed by the same logit expression. It follows that the emigrant-to-stayer ratio is given by:

$$
m_{i j, s, t} \equiv \frac{M_{i j, s, t}}{M_{i i, s, t}}=\left(\frac{w_{j, s, t}}{w_{i, s, t}}\right)^{\gamma} V_{i j, s, t},
$$

where $\gamma \equiv \frac{\tilde{\gamma}}{\mu}$, the elasticity of migration choices to wage disparities, is a combination of preference and distribution parameters, and $V_{i j, s, t} \equiv\left(\frac{v_{i j, s, t}}{v_{i i, s, t}}\right)^{1 / \mu}$ is a scale factor of the migration technology. The ratio of emigrants from $i$ to $j$ to stayers only depends on the characteristics of the two countries.

Production technology Income is determined based on an aggregate production function. Each country has a large number of competitive firms characterized by the same production technology and producing a homogenous good. The output in country $j, Y_{j, t}$, is a multiplicative function of the total quantity of labor in efficiency units, denoted by $L_{j, T, t}$, supplied by low-skilled and high-skilled workers by a "modified" total factor productivity (referred to as TFP henceforth), $A_{j, t}{ }^{7}$ Following the recent literature on labor markets, immigration and growth, ${ }^{8}$ we assume that labor in efficiency units is a CES function of the number of college-educated and less educated workers employed. We have:

\footnotetext{
${ }^{6}$ Bertoli and Moraga Fernandez-Huertas (2015), Bertoli and Moraga Fernandez-Huertas (2013) or Ortega and Peri (2013) used more general distributions, allowing for a positive correlation in the application of shocks across similar countries.

${ }^{7}$ In fact, there is a slight abuse of terms here as $A_{j, t}$ implicitly includes capital in supplement to the usual TFP, which is by definition the residual that explains a country's output level apart from capital and labor. This is why we define $A_{j, t}$ as a "modified TFP."

8 See Katz and Murphy (1992), Card and Lemieux (2001), Caselli et al. (2006), Borjas (2003), Borjas (2013), Card (2009), Ottaviano and Peri (2012), Docquier et al. (2015) among others.
} 


$$
Y_{j, t}=A_{j, t} L_{j, T, t}=A_{j, t}\left[\theta_{j, h, t} L_{j, h, t}^{\frac{\sigma-1}{\sigma}}+\theta_{j, l, t} L_{j, l, t}^{\frac{\sigma-1}{\sigma}}\right]^{\frac{\sigma}{\sigma-1}},
$$

where $\theta_{j, s, t}$ is the country and time-specific value share parameter for workers of type $s$ (such that $\theta_{j, h, t}+\theta_{j, l, t}=1$ ), and $\sigma$ is the common elasticity of substitution between the two groups of workers.

Firms maximize profits and the labor market is competitive. The equilibrium wage rate for type- $s$ workers in country $j$ is equal to the marginal productivity of labor:

$$
w_{j, s, t}=\theta_{j, s, t} A_{j, t}\left(\frac{L_{j, T, t}}{L_{j, s, t}}\right)^{1 / \sigma}
$$

Hence, the wage ratio between college graduates and less educated workers is given by:

$$
\frac{w_{j, h, t}}{w_{j, l, t}}=\frac{\theta_{j, h, t}}{\theta_{j, l, t}}\left(\frac{L_{j, h, t}}{L_{j, l, t}}\right)^{-1 / \sigma}
$$

As long as this ratio is greater than one, a rise in human capital increases the average productivity of workers. Furthermore, greater contributions of human capital to productivity can be obtained by assuming technological externalities. Two types of technological externality are factored in. First, we consider a simple Lucas-type, aggregate externality (Lucas 1988) and assume that the TFP scale factor in each sector is a concave function of the skill-ratio in the resident labor force. This externality captures the fact that educated workers facilitate innovation and the adoption of advanced technologies. Its size has been the focus of many recent articles and has generated a certain level of debate. Using data from US cities (Moretti 2004) or US states (Acemoglu and Angrist 2000; Iranzo and Peri 2009), some instrumentalvariable approaches give substantial externalities (Moretti 2004) while others do not (Acemoglu and Angrist 2000). In the empirical growth literature, there is evidence of a positive effect of schooling on innovation and technology diffusion (Benhabib and Spiegel 1994; Caselli et al. 2006; Ciccone and Papaioannou 2009). In parallel, another set of contributions highlights the effect of human capital on the quality of institutions (Castelló-Climent 2008; Bobba and Coviello 2007; Murtin and Waczi$\arg 2014)$. We write:

$$
A_{j, t}=\lambda_{t} \bar{A}_{j}\left(\frac{L_{j, h, t}}{L_{j, l, t}}\right)^{\epsilon},
$$

where $\lambda_{t}$ captures the worldwide time variations in productivity (common to all countries), $\bar{A}_{j}$ is the exogenous country-specific component of TFP in country $j$ (reflecting exogenous factors such as arable land, climate, geography, etc.), and $\epsilon$ is the elasticity of TFP to the skill ratio.

Second, we assume skill-biased technical change. As technology improves, the relative productivity of high-skilled workers increases (Acemoglu 2002; Restuccia 
and Vandenbroucke 2013). For example, Autor et al. (2003) show that computerization is associated with a declining relative demand in industry for routine manual and cognitive tasks, and increased relative demand for non-routine cognitive tasks. The observed relative demand shift favors college versus non-college labor. We write:

$$
\frac{\theta_{j, h, t}}{\theta_{j, l, t}}=\bar{Q}_{j}\left(\frac{L_{j, h, t}}{L_{j, l, t}}\right)^{\kappa},
$$

where $\bar{Q}_{j}$ is the exogenous country-specific component of the skill bias in productivity in country $j$, and $\kappa$ is the elasticity of the skill bias to the skill ratio.

Competitive equilibrium The link between the native and resident population is tautological:

$$
\sum_{j} N_{j, s, t}=\sum_{j} L_{j, s, t}=\sum_{i} \sum_{j} m_{i j, s, t} M_{i i, s, t}
$$

The dynamics of the world economy is governed by a succession of temporary equilibria defined as:

Definition - For a set $\left\{\gamma, \sigma, \epsilon, \kappa, \lambda_{t}\right\}$ of common parameters, a set $\left\{\bar{A}_{j}, \bar{Q}_{j}\right\}_{\forall j}$ of country-specific parameters, a set $\left\{V_{i j, s, t}\right\}_{\forall i, j, s}$ of bilateral (net) migration costs, and for given distribution of the native population $\left\{N_{j, s, t}\right\}_{\forall j, s}$, a temporary competitive equilibrium for period $t$ is an allocation of labor $\left\{M_{i j, s, t}\right\}_{\forall i, j, s}$ and a vector of wages $\left\{w_{j, s, t}\right\}_{\forall j, s}$ satisfying (i) utility maximization conditions, Eq. (4), (ii) profit maximization conditions, Eq. (6), (iii) technological constraints, Eqs. (8) and (9), and (iv) the aggregation constraints, Eq. (10).

A temporary equilibrium allocation of labor is characterized by a system of $2 \times J \times(J+1)$ i.e., $2 \times J \times(J-1)$ bilateral ratio of migrants to stayers, $2 \times J$ wage rates, and $2 \times J$ aggregation constraints. In the next sub-sections, we use data for 180 countries (developed and developing independent territories) and explain how we parameterize our system of 65,160 simultaneous equations per period. Once properly calibrated, this model can be used to conduct a large variety of numerical experiments.

Parameterization for the year 2010 The year 2010 is the most recent year for which skill-specific matrices of bilateral migration stocks are available. The model can be parameterized to match the economic and socio-demographic characteristics of 180 countries as in the year 2010 .

Regarding the production technology, we collect data on GDP in PPP values $\left(Y_{j, 2010}\right)$ from the Maddison's project described in Bolt and Van Zanden (2014), and combine them with data on the size and structure of the labor force from the Wittgenstein Centre for Demography and Global Human Capital $\left(L_{j, s, 2010}\right)$, and data on the wage ratio between college graduates and less educated workers, $\frac{w_{j, h, 2010}}{w_{j, l, 2010}}$, from 
Hendricks (2004). ${ }^{9}$ The labor force is proxied by population aged 25 to 64 . Using these data, we proceed in three steps to calibrate the production technology. First, in line with the labor market literature (Ottaviano and Peri 2012; Angrist 1995), we assume that the elasticity of substitution between college-educated and less educated workers, $\sigma$, is equal to 2 or 3 . Second, for a given $\sigma$, we calibrate the ratio of value shares, $\frac{\theta_{j, h, 2010}}{\theta_{j, l, 2010}}$, as a residual from Eq. (7) to match the observed wage ratio. Since $\theta_{j, h}+\theta_{j, l}=1$, this determines both $\theta_{j, h, 2010}$ and $\theta_{j, l, 2010}$ as well as the quantity of labor per efficiency unit, $L_{j, T, 2010}$, defined in Eq. (5). Third, we use Eq. (5) and calibrate the TFP level, $A_{j, 2010}$, to match the observed GDP and we normalize $\lambda_{2010}$ to unity (without loss of generality). When simulating the model backward or forward (see below), we consider several variants for $\epsilon$ and for $\kappa$, allowing the ratio of value shares and the TFP level vary with the skill ratio. When all technological parameters are calibrated, we use Eq. (6) to proxy the wage rates for each skill group.

As for the migration technology, we use the DIOC-E database of the OECD. DIOC-E builds on the Database on Immigrants in OECD countries (DIOC) described in Arslan et al. (2015) where migrants are defined as foreign-born population. The data are collected by country of destination and are mainly based on population censuses or administrative registers. The DIOC database provides detailed information on the country of origin, demographic characteristics and level of education of the population of 34 OECD member states. DIOC-E extends the latter by characterizing the structure of the population of 86 non-OECD destination countries. Focusing on the populations aged 25 to 64 , we thus end up with matrices of bilateral migration from 180 origin countries to 120 destination countries (34 OECD +86 non-OECD countries) by education level, as well as proxies for the native population $\left(N_{i, s, 2010}\right)$. We assume that immigration stocks in the 60 missing countries are zero, which allows us to compute comprehensive migration matrices. ${ }^{10}$

Regarding the elasticity of bilateral migration to the wage ratio, $\gamma$, Bertoli and Moraga Fernandez-Huertas (2013) find a value between 0.6 and 0.7. We use 0.7 as a benchmark but other values ( 0.5 or 1.0$)$ are considered in our robustness checks. Finally, we calibrate $V_{i j, s, 2010}$ as a residual of Eq. (4) to match the observed ratio of bilateral migrants to stayers. In Appendix A, we show that the calibrated scale factors are negatively correlated with standard determinants of migration costs such as geographic distance, migration policy, etc.

\footnotetext{
9 When missing, the latter are supplemented using the estimates of Docquier et al. (2015).

10 The 60 destinations that do not have any migrant recorded in our dataset are: Afghanistan, Algeria, Angola, Azerbaijan, Bahamas, Bangladesh, Barbados, Bhutan, Bosnia and Herzegovina, Brunei, Burundi, Cape Verde, Central African Republic, Chad, Congo D.R., Congo R, Djibouti, East Timor, Equatorial Guinea, Eritrea, Ethiopia, Gabon, Guinea-Bissau, Guyana, Haiti, Jordan, Korea, Lebanon, Lesotho, Libya, Macedonia, Madagascar, Maldives, Mauritania, Micronesia, Moldova, Morocco, Myanmar, Nigeria, Occupied Palestinian Territory, Pakistan, Papua New Guinea, St. Lucia, St. Vincent and the Grenadines, Samoa, Sao Tome and Principe, Singapore, Solomon Islands, Somalia, Suriname, Swaziland, Syria, Tonga, Tunisia, Turkmenistan, Uzbekistan, Vanuatu, Vietnam, Yemen, Zimbabwe. None of these destinations is an important immigration country.
} 
In sum, the migration and technology parameters are such that our model perfectly matches the world distribution of income, the world population allocation and skill structure as well as bilateral migration stocks as of the year 2010 .

Caveats Our model relies on simplifying assumptions that may, at first, seem unrealistic but do not, arguably, invalidate our results. Firstly, although one period is meant to represent 10 years, we assume a "drawing-with-replacement" migration process. This means that we ignore path dependency in migration decisions (i.e., having migrated to country $j$ at time $t$ influences the individual location at time $t+1$ ), as if all migrants returned to their home country at the end of each period $t$, and made new migration decisions at the beginning of period $t+1$. This simplification is compatible with the existence of both temporary and permanent migrants although it disregards differences between them. This "drawing-with-replacement" migration hypothesis allows us to model the trends in migration stocks as a simple function of concomitant population trends and without keeping track of the entire log of past migration flows. ${ }^{11}$ This is why we can compute the competitive equilibrium as a succession of temporary equilibria.

Secondly, the migration technology is calibrated using migration stock data, which are assumed to reflect the long-run migration equilibrium. This implies that the calibrated values for $V_{i j, s, t}$ implicitly account for net amenity differentials, private and visa costs of migration, and network effects (i.e., the effect of past migration stocks on migration flows). Migration costs are expressed as a disutility. They include monetary moving costs (e.g., passport and travel costs) a well as utility-loss equivalents of migration quotas (similar to tariff equivalent of non-tariff barriers in trade). These costs are treated as exogenous. ${ }^{12}$

Thirdly, the model is calibrated to match labor force and migration stock data by education level, assuming that these stocks are proxied by the number of individuals aged 25-64. We thus consider individuals aged 25-64 as a homogenous group and abstract from the heterogeneity in the propensity to migrate across age groups. We are aware that individuals aged 20-34 are more migratory than older age groups (Hatton and Williamson 1998; UNDESA 2013) due to higher present values of migration in intertemporal utility function (Hatton and Williamson 2011; Djajic et al. 2016). However, in Appendix A, we show that the past variations in the population aged 20-34 are highly correlated with past variations in the population aged 25-64. The correlation equals 0.77 over the period 1970-2010 and the slope of the regression line is close to unity. Similarly, when using the medium variant of the UN population projections, this correlation equals 0.70 over the long period of 2010-2100. Hence, variations in the population aged 25 to 64 capture well the migration pressures related to demographic factors.

Fourthly, our model without physical capital features a globalized economy with a common international interest rate. This hypothesis is in line with Kennan (2013)

\footnotetext{
11 Which is implicitly captured by the level of dyadic net migration costs, $V_{i j, t, s^{*}}$.

12 In practice, visa restrictions are likely to depend on the intensity of immigration pressures as well as on origin and/or destination countries' characteristics.
} 
or Klein and Ventura (2009) who assume that capital "chases" labor. ${ }^{13}$ Eq. (5) can be seen as the reduced form of a system of two equations, a first-stage production function with capital and labor (e.g., in the Cobb-Douglas case, $Y_{j, t}=\tilde{A}_{j, t} K_{j, t}^{\alpha} L_{j, T, t}^{1-\alpha}$ where $\tilde{A}_{j, t}$ is the actual TFP level of country $j$ at time $t$ ) and an arbitrage condition implying that the interest rates are equalized across countries $\left(R_{t}=\tilde{A}_{j, t} \alpha K_{j, t}^{\alpha-1} L_{j, T, t}^{1-\alpha}\right)$. Substituting the arbitrage equation into the first-stage production function gives Eq. (5), in which the "modified" TFP level is defined as $A_{j, t}=\tilde{A}_{j, t}^{1 /(1-\alpha)}\left(\alpha / R_{t}\right)^{\alpha /(1-\alpha)}$. Clearly, changes in the international interest rate $R_{t}$ or multiplicative changes in TFP level (due to exogenous technological progress, $\lambda_{t}$ ) have no effect on the ratio of "modified" TFP and on the ratio of wage rates between two countries. From Eq. (4), they have no effect on migration behaviors.

\section{Backcasting and nowcasting}

Our first objective is to gauge the ability of our model to replicate aggregate historical and contemporaneous migration data as well as to backcast the educational structure of past migration stocks. In our backcasting exercises, we use the model to simulate retrospectively bilateral migration stocks by education level, and compare the results with proxies of observed migration stocks for the years 1970, 1980, 1990 and $2000 .{ }^{14}$ Similarly, we test the performance of our nowcasts by comparing the data predicted by our model for the year of 2020 with the most recent migration data of 2019 obtained from the United Nations Global migration database. To do so, we feed the model with two types of inputs, namely skill-specific wage rates and levels of the native (pre-migration) population for all countries. In the nowcasting simulation, we use the population estimates for 2020 from Lutz et al. (2017), as in the forecasting section. ${ }^{15}$ These backasting and nowcasting exercises shed light on the relevance our parameterization strategy (i.e. what value for $\gamma, \sigma$ and $\kappa$ should be favored?) and on the role of socio-demographic and technological changes in explaining the aggregate variations in past migration.

Worldwide migration stocks Figure 1 illustrates the backcasting and nowcasting results obtained for the worldwide stock of working-age migrants in our benchmark scenario with $\gamma=0.7, \sigma=2$, and $\kappa=0.214$. In particular, Fig. 1a compares the evolution of actual and predicted worldwide migration stocks by decade for the year 1970 to 2020 . For the $180 \times 120$ corridors, the (rescaled) data gives a stock of 55 million migrants aged 25 to 64 in 1970, 120 million migrants in 2010, and 141 million migrants in 2020. Our benchmark model almost exactly matches this evolution. By construction, the model perfectly matches the 2010 data. Interestingly, it almost

\footnotetext{
13 Interestingly, Ortega and Peri (2009) find that capital adjustments are rapid in open economies: an inflow of immigrants increases one-for-one employment and capital stocks in the short term (i.e. within one year), leaving the capital/labor ratio unchanged.

14 Appendix C.2 provides details on the computation of these proxies.

15 Note that the pre-migration population levels are not directly observable but they can be identified as outcomes of our model, as explained in Appendix C.1.
} 
perfectly matches the data for the years 1970 and $2020,{ }^{16}$ while it slightly overestimates the stock in 1980, 1990 and 2000.

We see this result as evidencing the realism of the model. In Appendix C.2, we check whether the model's aggregate performance depends on the parameter set. We produce backcasts under 18 scenarios, considering three possible values for $\gamma(0.5$, 0.7 and 1.0), two possible values for $\sigma$ (2.0 and 3.0) and three possible values for $\kappa$ ( 0 , half the estimated elasticity of the value shares to the skill ratio, and $100 \%$ of the estimated elasticity). Figure C. 1 shows that the model with $\gamma=0.7$ gives the best fit. Assuming $\gamma=1.0$ leads to an overestimation of past migrant stocks, while $\gamma=0.5$ leads to an underestimation. By contrast, our backcasts are fairly robust to the choice of $\sigma$, the elasticity of substitution between workers, and of $\kappa$, the skill-biased externality. Although technological variants drastically affect within-country income disparities (in particular, the wage ratio between college graduates and the less educated), they have negligible effects on aggregate migration stocks. This is due to the fact that income disparities are mostly governed by between-country inequality (i.e., by the TFP levels, which are calibrated under each scenario to match the average levels of income per worker), and that the worldwide proportion of college graduates is so small that changes in their migration propensity have negligible effects on the aggregate.

Coming back to the benchmark scenario with $\gamma=0.7, \sigma=2$ and $\kappa=0.214$, Fig. 1b compares our backcasts for the years 1970 to 2000 with counterfactual retrospective simulations. The first counterfactual neutralizes demographic changes that occurred between 1970 and 2010; it assumes that the size of the working age population is kept constant at the 2010 level in all countries. The second counterfactual neutralizes the changes in education; it assumes that the share of college graduates is kept constant in all countries. The third counterfactual neutralizes the changes in income disparities; it assumes constant wage rates in all countries.

On the one hand, the simulations reveal that past changes/rises in education marginally increased the worldwide migration stock, while the past changes/decreases in income inequality marginally reduced it. These effects are quantitatively small, which does not mean that cross-country disparities in education and income have no influence on migration trends. It is because past changes in human capital has been limited in poor countries, and income disparities have been stable for the last fifty years (with the exception of emerging countries). Hence, the contribution of these two factors has been limited.

On the other hand, Fig. 1b shows that demographic changes explains a large amount of the variability in migration stocks. The number of worldwide migrants in 1970 would have almost been equal to the current stocks (in fact, it would have been $2 \%$ smaller only) if the population size of each country had been identical to

\footnotetext{
16 Table C.2 in the Appendix C. 3 shows that the actual total number of migrants of 2019 is 141 million. All of our predicted numbers for the year 2020 are only slightly higher. In the benchmark scenario where we consider the demographic scenario SSP2, $\gamma=0.7, \sigma=2$ and full technological externalities, our predicted number of world migrants reaches 142 million in 2020. The correlation between the actual and predicted immigrants by destination and emigrants by origin is also very high (more than 0.94).
} 
(a) Actual and predicted migrant stocks, 1970-2020

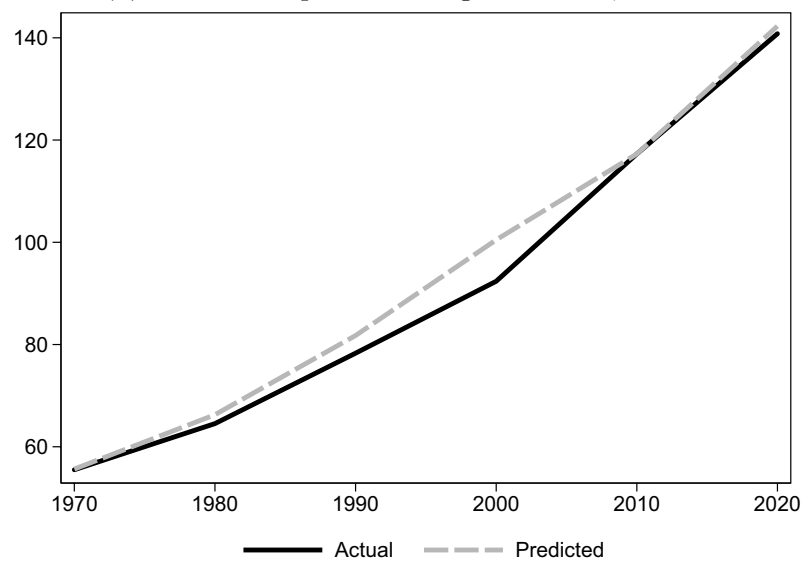

(b) Counterfactual historical stocks, 1970-2010

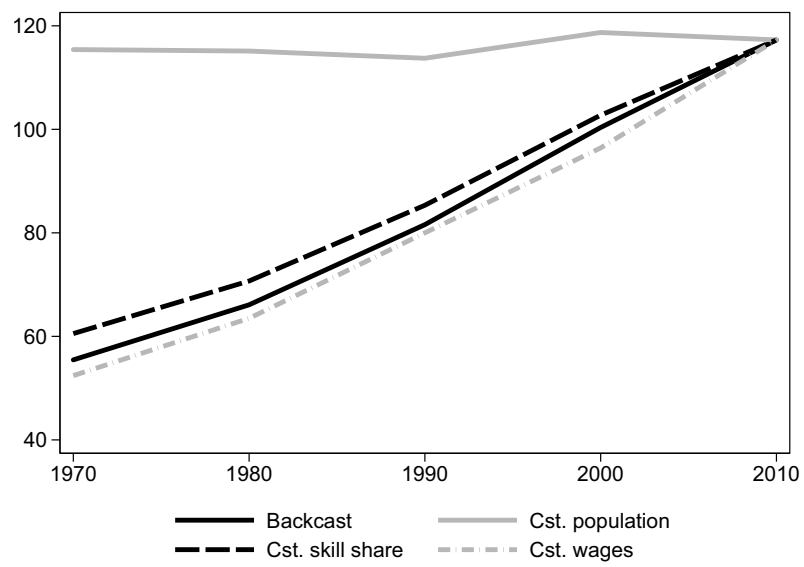

Fig. 1 Actual and predicted migrant stocks (in million). a Actual and predicted migrant stocks, 19702020. b Counterfactual historical stocks, 1970-2010. Note: Fig. a compares actual and predicted stocks of working-aged migrants. To obtain the actual working-age migrant stocks, we use the share of working-aged migrants in 2010 to rescale the total migrant stocks from Ozden et al. (2011) for the years 1960-2000 and from the UNPOP database for the year 2020. Predicted migrants stocks are computed from the scenario in which $\gamma=0.7, \sigma=2$, and $\kappa=0.214$. In Fig. $\mathbf{b}$, the first counterfactual keeps the size of the working-age population constant at the 2010 level in all countries. The second counterfactual keeps the share of college graduates constant at the 2010 level in all countries. The third counterfactual keeps wage rates constant at the 2010 level in all countries

the current level. This confirms that past changes in aggregate migrant stocks were predominantly governed by population growth in LDCs and demographic imbalances. Indeed, the population ratio between developing and high-income countries increased from 3.5 in 1970 to 5.5 in 2010.

Bilateral migration backcasts We now investigate the capacity of the model to match the decadal distributions of immigrant stocks by destination, and the decadal 
(a) Immigrant stocks by dest. (in logs) (b) Emigrant stocks by origin (in logs)
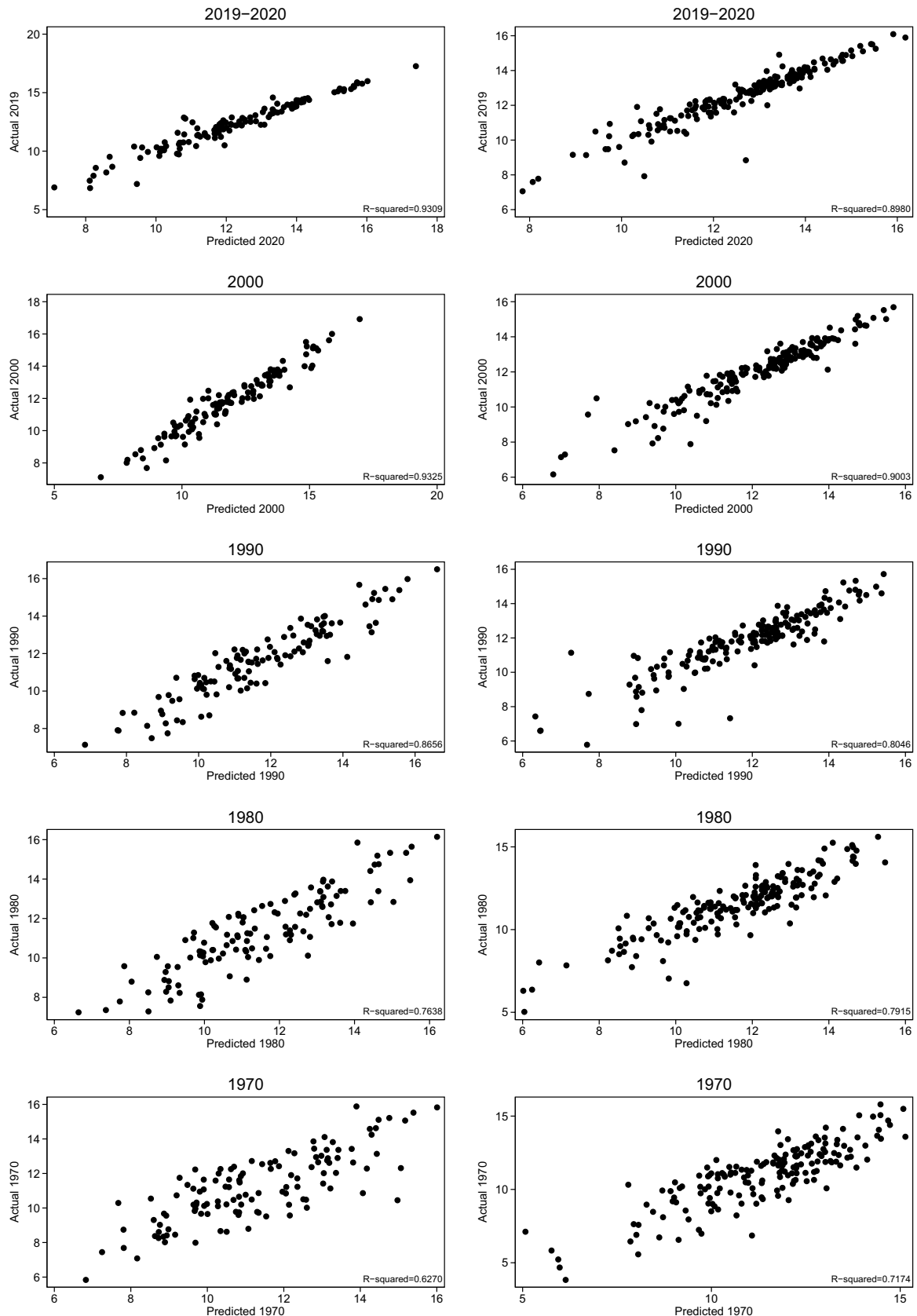

Fig. 2 Comparison between actual and predicted migrant stocks, 1970-2020 a Immigrant stocks by dest. (in $\log$ ). b Emigrant stocks by origin (in logs). Note: Authors' computations based on the variant with $\gamma=0.7, \sigma=2$ and $\kappa=0.214$ 
distributions of emigrant stocks by origin. Figure 2 provides a graphical visualization of the goodness of fit by comparing the observed and simulated bilateral stocks of immigrants and emigrants for each decade. ${ }^{17}$

By construction, as the observed past immigration stocks of all ages are scaled to match the working-age ones in 2010, the predicted immigrant stocks are perfectly matched in that year. For previous years, the correlation is unsurprisingly smaller; it decreases with the distance from the year 2010. This is because our model does neither identify past variations in migration policies (e.g. the Schengen agreement in the European Union, changes in the H1B visa policy in the US, the points-system schemes in Canada, Australia, New Zealand, guest worker programs in the Persian Gulf, etc.) nor past changes in net amenities and non-pecuniary push/pull factors (e.g., conflicts, political unrest, etc.). The biggest gaps between the observed and predicted migration stocks recorded in our data come from the non-consideration of the collapse of the Soviet Union, the end of the French-Algerian war and of the Vietnam war, the conflict between Cuba and the US. In addition, the model imperfectly predicts the evolution of intra-EU migration, the evolution of labor mobility to Persian Gulf countries, the evolution of migrant stocks from developing countries to the US, Canada and Australia, and the evolution of immigration to Israel (especially the flows of Russian Jews after the late 1980 - the so-called Post-Soviet aliyah).

Yet, the scatterplots on Fig. 2 show high correlations between the observed and predicted bilateral migration volumes throughout all decades. The lowest reported R-squared are 0.76 for immigrant stocks and 0.69 for emigrant stocks in 1970 . These numbers reach 0.93 and 0.90 , respectively, for the years 2000 and 2020. This demonstrates that the constant $V_{i j}$ hypothesis does a good job on average despite big changes in immigration policies in the past whose restrictiveness was either increasing or decreasing. ${ }^{18}$ In the former case, it may be that stricter entry policies have been balanced by increasing network effects.

As far as the technological variants are concerned, Table C.1 in Appendix C. 2 confirms that they play a negligible role. The correlation between variants is always around 0.99 . The variant with $\sigma=2$ and no skill-biased externality marginally outperforms the others in replicating immigrant stocks; the one with $\sigma=3$ and with skill biased externalities does a slightly better job in matching emigrant stocks. Hence, the backcasting exercise shows that our model does an excellent job in explaining the long term evolution of migration stocks; however, it does not help

\footnotetext{
17 Table C. 1 in the in the Appendix C. 2 provides the coefficient of correlation between our backcasts for 1970-2000 and the actual observations aggregate at country level for each decade and for different parameter sets. It evidences the robustness of the model to different technological scenarios.

18 In the late 20th century from 1970 to 2000, we document both forms of tighter and loosened immigration policies in major receiving countries. In Western Europe, the Guest Worker program came to an end following the 1973-4's oil crisis. While in the US, a series of immigration acts were introduced allowing more entry of family immigrants (the 1990 Immigration Act), legalization of illegal immigrants (the 1986 Reform and Control Act) (see Clark et al. (2007) for an overview) before immigration policies became restrictive again after the September 11 attacks in 2001. The third wave of immigration to the Gulf region also took place during this period after 1971-year of official independence of GCC countries from the United Kingdom-where mass industrialization and modernization have led to large importation of foreign workers.
} 
eliminate irrelevant technological scenarios. Regressing the log of actual immigration stocks on their predicted levels per decade, we obtain regression coefficients that are not significantly different from unity, with standard errors around 0.004 for the years 2000 and 2020, around 0.006 for 1990, 0.008 for 1980 and 0.010 for 1970 . Roughly speaking, this means that the $95 \%$ confidence interval surrounding our predictions increases by about $0.4 \%$ per decade departing from 2010 . For 1970 (4 decades before the calibration year), there is a $95 \%$ probability that the observed migration stocks are comprised between 98 and $102 \%$ of our predicted levels.

Backcasts by skill group Data on migration stocks by educational level are available for a few decades only. The DIOC database of Arslan et al. (2015) provides homogeneous data for the census rounds 2000 and 2010. In Appendix C.2, we show that our model replicates well the changes in the educational structure of migration stocks observed between two census rounds. As migration data by skill group do not exist for earlier periods, we use our model to backcast the global net flows of college-educated and less educated workers between regions. We use the scenario with $\gamma=0.7, \sigma=2$ and with full skill-biased externalities. ${ }^{19}$ For each pair of countries, we compute the net flow as the difference between the stock of migrants in 2010 and that of $1970, \Delta M_{i j, s} \equiv M_{i j, s, 2010}-M_{i j, s, 1970}$. These net flows form the matrix $\mathcal{M}$. On Fig. 3, we group countries into eight regions and use circular ideograms following Krzywinski et al. (2009) to highlight the major components of $\mathcal{M}$. Net flows are colored according to their origin, and their width is proportional to their size. The direction of the flow is captured by the colors of the outside (i.e., country of origin) and inside (i.e., country of destination) borders of the circle.

We also characterize the clusters of origins and destinations that caused the greatest variations in global migration between 1970 and 2010. Using the same matrix of migration net flows as above (denoted by $\mathcal{M}$ and including the $J \times J$ net flows between 1970 and 2010, $\Delta M_{i j, s}$ ). We use the Max-Sum Submatrix algorithm defined in Appendix B, a standard tool in applied mathematics which is used to identify the sub-matrix with a fixed dimension $o \times d$ that maximizes the total migration net flows (i.e., that captures the greatest fraction of the worldwide variations in migration stocks).

Figure $3 \mathrm{a}$ focuses on the net flows of less educated workers. The net flow of lowskilled immigrants equals 35.2 million over the 1970-2010 period. The ten main regional corridors account for $79 \%$ of the total, and industrialized regions appear 6 times as a main destination. By decreasing the order of magnitude, they include Latin America to North America (27.6\%), migration within the South and East Asian region (13\%), from MENA to Europe (6.8\%), migration between former Soviet countries (5.2\%), migration within sub-Saharan Africa (5.1\%), intra-European movements (4.5\%), Latin America to Europe (4.4\%), South and East Asia to Western offshoots (4.2\%), Others to Europe (4.0\%), and migration between Latin

\footnotetext{
19 Assuming $\kappa$ is large, we may overestimate the causal effect of the skill ratio on the ratio of value shares. However, disregarding causation issues, this technological scenario is the most compatible with the cross-country correlation between human capital and the wage structure: it fits the cross-country correlation between the skill bias and the skill ratio in the year 2010.
} 
American countries (4.0\%). It is worth noting the low-skilled mobility from subSaharan Africa to Europe is not part of the top ten: it only represents $3.8 \%$ of the total (the 11th largest regional corridor). Applying the Max-Sum submatrix problem to the net flows of low-skilled migrants, we can identify the 25 origins and the 25 destinations (625 entries) that account for $64 \%$ of the worldwide net flows of lowskilled migrants between 1970 and 2010 .

- The 25 main destinations (in alphabetical order) are: Australia, Austria, Belarus, Belgium, Canada, Dominican Republic, France, Germany, Greece, Hong Kong, India, Israel, Italy, Kazakhstan, Malaysia, Nepal, the Netherlands, Oman, Russia, Saudi Arabia, Spain, Thailand, the United Kingdom, the United States, and Venezuela.

- The 25 main origins (in alphabetical order) are: Albania, Algeria, Bangladesh, Colombia, the Dominican Republic, Ecuador, Guatemala, Haiti, India, Indonesia, Jamaica, Kazakhstan, Mexico, Morocco, Myanmar, Pakistan, the Philippines, Poland, Romania, Russia, Slovenia, Turkey, Ukraine, Uzbekistan, and Vietnam.

Figure $3 \mathrm{~b}$ represents the net flows of college graduates. The net flow of highskilled immigrants equals 27.6 million over the 1970-2010 period. The ten main regional corridors account for $74 \%$ of the total. A major difference with the lowskilled is that industrialized regions appear 9 times as a main destination, at least if we treat the Persian Gulf countries (as part of the MENA region) as industrialized. By decreasing order of magnitude, the top-10 includes South and East Asia to Western offshoots (19.8\% of the total), intra-European movements $(10.7 \%)$, migration between former Soviet countries $(10.5 \%)$, Latin America to Western offshoots (9.7\%), Europe to Western offshoots (6.5\%), South and East Asia to Europe (4.6\%), MENA to Europe (3.3\%), sub-Saharan Africa to Europe (3.2\%), South and East Asia to the MENA (3.1\%), and Latin America to Europe (2.9\%). Applying the MaxSum submatrix problem to the net flows of low-skilled migrants, the set of main destinations mostly includes high-income countries. The 625 entries of the Max-sum submatrix account for $55 \%$ of the worldwide net flow of college-educated migrants between 1970 and 2010.

- The 25 main destinations (in alphabetical order) are: Australia, Austria, Belarus, Canada, France, Germany, India, Ireland, Israel, Italy, Japan, Kazakhstan, the Netherlands, New Zealand, Oman, Russia, Saudi Arabia, Spain, Sweden, Switzerland, Thailand, Ukraine, the United Arab Emirates, the United Kingdom, and the United States.

- The 25 main origins (in alphabetical order) are: Algeria, Bangladesh, Canada, China, Colombia, Egypt, France, Germany, India, Iran, Japan, Kazakhstan, Mexico, Morocco, Pakistan, the Philippines, Poland, Romania, Russia, South Korea, Ukraine, the United Kingdom, the United States, Uzbekistan, and Vietnam.

Overall, as shown in the left panel of Table 2 below, the model predicts that the proportion of college graduates in the total immigrant stocks of the OECD countries rose from 13.3 to $34.0 \%$ between 1970 and 2010 . It increased from 10.8 to $28.4 \%$ 
(a) Less educated workers

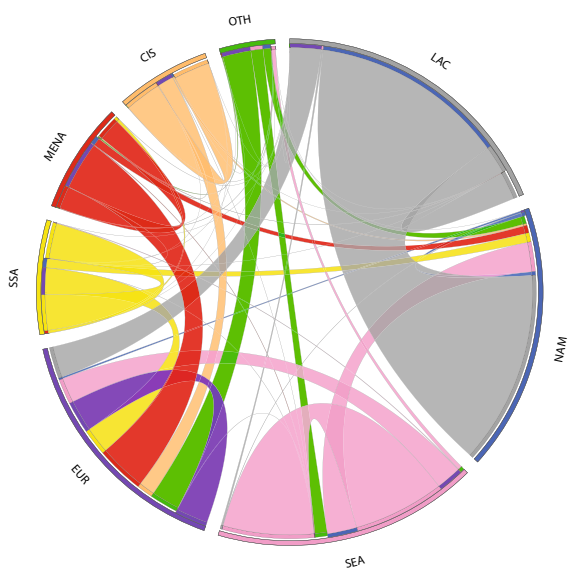

(b) College-educated workers

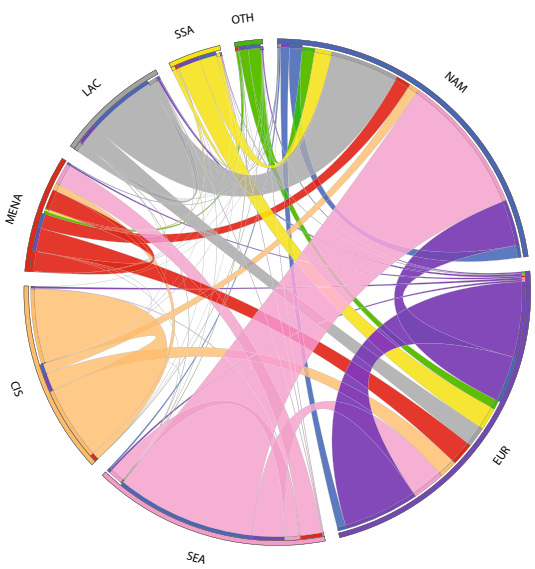

Fig. 3 Global migration net flows, 1970-2010. a Less educated workers. b College-educated workers. Regions: Europe (in dark blue), Western offshoots (NAM in light blue)(These include the United States, Canada, Australia and New Zealand), the Middle East and Northern Africa (MENA in red), sub-Saharan Africa (SSA in yellow), South and East Asia including South and South-East Asia (SEA in pink), the former Soviet countries (CIS in orange), Latin America and the Caribbean (LAC in grey), and Others (OTH in green). Net flows are colored according to their origin, and their width is proportional to their size. The direction of the flow is captured by the colors of the outside (i.e., country of origin) and inside (i.e., country of destination) borders of the circle (color figure online)

in EU15, from 13.9 to $34.4 \%$ in the United States. Larger changes were observed in Canada, Australia or the United Kingdom.

\section{Forecasting}

We now use the parameterized model to produce projections of migration stocks and income disparities for the 21st century. Availability of population projections until the end of the century allows us to systematically predict migration for that entire period, though the longer the distance from 2010, the more uncertain are our projections. Extrapolating insights from our backcasting exercice, there would be a $95 \%$ probability that actual migration stocks will be comprised between 98 and $102 \%$ of our predicted levels 40 years after the calibration year (i.e., in 2050), and between 95 and $105 \%$ of our predicted stock around the year 2100 (as the confidence interval increases by $0.4 \%$ per decade). This is at least what we obtain when the spatial and socio-demographic structure of the world population is observable. Hence, when turning our attention to forecasts, an additional source of uncertainty relates to the evolution of other socio-demographic variables. Below, we first describe our two main projection scenarios. We then discuss the global trends in international migration and income inequality generated by these two scenarios, with a special focus on migration flows to OECD countries, before discussing the policy options than can be used to curb future migration pressures. 
Projection scenarios We feed our model with two socio-demographic scenarios obtained from the Wittgenstein Centre for Demography and Global Human Capital (Lutz et al. 2017). ${ }^{20}$ The so-called Shared Socioeconomic Pathways (SSPs) have been designed to capture future trends with respect to education, fertility, mortality and socioeconomic challenges (e.g., climate change mitigation and adaptation strategies). We use two scenarios, SSP2 and SSP3, that involve a strong negative association between the level of (female) education and both fertility and (child) mortality rates. The empowerment of women through education is key: it translates into significant changes in attitudes and behaviors. In high fertility countries it brings down birth rates and improves the survival of children. However, the effect of this better education on population growth is delayed because of two factors. First, if more girls get educated today, the effect on fertility will occur some 15 years later, when they will be in their child-bearing years. Second, the decrease in fertility rates does not translate immediately into falling absolute numbers of births because of the large age-structural momentum of population growth. Hence, differences between the two scenarios become visible only after a few decades (after 2050). SSP2 and SSP3 are defined below (Lutz et al. 2017):

- Scenario SSP2 (Continuation/Medium Population Scenario) is "the middle-ofthe-road scenario in which trends typical of recent decades continue, with some progress toward achieving development goals [...]. Development of low income countries is uneven, with some countries making good progress, while others make less." It is assumed that each country will follow the average path of school expansion that advanced countries have experienced.

- Scenario SSP3 (Fragmentation/Stalled Social Development) "portrays a world separated into regions characterized by extreme poverty, pockets of moderate wealth, and many countries struggling to maintain living standards for rapidly growing populations." SSP3 is based upon the assumption that everywhere the most recently observed rates of school enrolment are frozen at their current levels. As compared with SSP2, SSP3 is characterized by an higher increase in the world population together with a lower educational level, and delayed demographic transition (higher fertility and mortality rates).

In the benchmark simulations, we also assume constant migration costs and amenity differentials $V_{i j, s, 2010}$ - which appears to be a reasonable working hypothesis in the backcasting exercise - and a constant technological progress of $1.5 \%$ per year. The latter hypothesis has no incidence on migration decisions as it affects all countries in a symmetric way. The hypothesis of constant migration costs will be relaxed in the end of the section. Our forecasts do not account for future conflict, climate shocks or natural disasters. ${ }^{21}$ Future efforts should incorporate those elements. Finally,

\footnotetext{
20 More details about these scenarios are provided in Appendix D.

21 For instance, Missirian and Schlenker (2014) show that asylum applications increased when global temperatures rose, Desmet et al. (2018) predict how local sea-level changes affect human displacement. Burzynski et al. (2019) predict that 210 to 320 million people will be forced or incentivized to move over the 21 st century. However, under constant migration policies, climate migrants will move first from
} 
we acknowledge the reverse impacts of migration on population growth in sending countries due to change in demographic structure and transfer of reproductive norms. They are however not accounted for in this paper, which takes socio-demographic scenarios as given in order to analyze their effects on income and migration.

Global implications We first highlight the implications of these two socio-demographic scenarios for income growth, global inequality and migration pressures. The global income and migration forecasts are depicted on Fig. 4, which combines the data for the period 1970-2010, and the model forecasts for the subsequent years. Two scenarios of SSP2 and SSP3 are presented in this Fig. 4, both with $\sigma=2.0$, $\gamma=0.7$, and full technological externalities, i.e. $\kappa=0.214$ and $\epsilon=0.207 .^{22}$

Let us first focus on income projections. Figure $4 \mathrm{a}$ shows the evolution of the worldwide level of GDP per worker. Under SSP3, the average GDP/worker in 2050 is 1.5 times higher than the level of 2010 (and 2.4 times greater in 2100). Under SSP2 and due to the rise in the level of schooling, the average GDP/worker in 2050 is twice as high as the level of 2010 (and 3.5 times greater in 2100). ${ }^{23}$ Figure $4 \mathrm{~b}$ describes the evolution of the Theil index between 1970 and 2100. We combine our backcasts, nowcasts and forecasts, and account for between-country inequality and within-country inequality (between the college-educated and less educated representative workers, only). Globally, we show that the Theil index decreases from 1970 to 2010, a phenomenon that can be due to convergence in the productivity scale factors between high-income and emerging countries. Our projections do not account for convergence forces that are not driven by human capital. Under SSP2, the model predicts that the Theil index is constant over time, or is increasing slightly when externalities are included. Under SSP3, we predict an increase in the Theil index.

Figure 4c, d depict the evolution of the worldwide proportion of international migrants and of the skill structure of migration. Under SSP3, the proportion of migrants (ranging from 3.6 and 3.9\%) and the share of college-educated (around $30 \%$ ) are fairly stable. By contrast, under SSP2, progress in education makes people more mobile. Under constant migration policies, the proportion of migrants increases from $3.6 \%$ in 2010 to $4.5 \%$ in 2050 and to $6.0 \%$ in 2100, and the share of college graduates increases from $29 \%$ in 2010 to $34 \%$ in 2050 and to $70 \%$ in 2100 . It is worth noticing that the important gap between the worldwide proportions of migrants in SSP2 and SSP3 does not result from a big difference in terms of worldwide migrant volume. The global stock of migrants amounts to 117 million in 2010 .

\footnotetext{
Footnote 21 (continued)

rural to urban areas, within their own countries, before moving across borders (Maurel and Tuccio 2015). Existing literature suggests that massive international flows of climate refugees are unlikely, except under generalized and persistent conflicts over resources (Rigaud et al. 2018).

22 Additional results of different technological scenarios are presented in the Figure D.2 in the Appendix D.2. Under SSP3, worldwide changes in human capital are negligible; eliminating technological externalities hardly modifies the results. Under SSP2, technological scenarios play a more important role after 2050 but have little influence on global trends.

23 In Figure D.2 of the Appendix D.2, productivity growth is boosted when technological externalities are factored in. By contrast, assuming a higher level for $\sigma$ generates very similar income projections.
} 
Under SSP2, it reaches 205 million in 2050 and 257 million in 2100. Under SSP3, it equals 180 million in 2050 and 245 million in 2100 . This is because SSP2 and SSP3 involves drastically different demographic trends in the developing world. In 2010, the working-age population is estimated at 3.28 billion. Under SSP2, it will reach 4.67 billion by 2050 and 4.29 billion by 2100 . Under SSP3, it will reach 4.74 billion by 2050 , and 6.26 billion by 2100 .

As for the proportion of the high skill population, it should be recalled that our backcasts reveal that past changes in educational attainment were small in developing countries; they hardly affected the trajectory of global migration (see Fig. 1b). Figure $4 \mathrm{~d}$ illustrates the marked effect of human capital trends. SPP2 predicts large educational changes in the coming decades, with strong implications for the skill structure of global migration. ${ }^{24}$

We now focus on emigration and immigration rates, separately. Figure $4 \mathrm{e}$ depicts the evolution of emigration rates, defined as the ratio of emigrants to natives originating from developing countries. The average emigration rate equals $3.1 \%$ in 2010. Under SSP2, it is predicted to reach $4.1 \%$ in 2050 and to be twice as large in the year 2100; under SSP3, it reaches $3.6 \%$ only by the end of the century. As explained above, the emigration rate is governed by the change in the average level of education in the developing world. Under SSP2 progress in education makes people more mobile (remember college graduates migrate more than the less educated). Under SSP3 emigration rates remain fairly stable over time given the slower progress in education. Similar patterns emerge from Fig. 4c,e, suggesting that the world proportion of migrants is shaped by emigration rates from developing countries.

Finally, Fig. 4f depicts the evolution of the average fraction of immigrants in OECD member states, defined as the proportion of foreign-born in the total population. This proportion equals $12 \%$ in the year 2010 and it is expected to increase drastically over the 21 st century. Nevertheless, Figure D.2 in the Appendix D.2 points to a remarkable result that the magnitude of the change is highly insensitive to sociodemographic and technological scenarios. Under SSP3, emigration rates from developing countries vary little, but population growth is large. Under the SSP2 scenario, the rise in emigration rates is larger, but it is partly offset by the fall in the population growth rates of developing countries. Under SSP2, the share of immigrants to OECD countries reaches $19.2 \%$ by 2050 , and $27.5 \%$ by 2100 . Under SSP3, this number reaches $16.9 \%$ by 2050 , and $24.6 \%$ by 2100 .

Implications for $\mathbf{H I}$ countries Table 1 provides projections of immigration rates for the main high-income, destination countries under constant immigration policies. Remember this hypothesis performed well when producing backcasting results. Results obtained under the SSP2 socio-demographic scenario are presented in the top panel; results obtained under SSP3 are presented in the bottom panel. In both cases, we consider the variant with $\sigma=2$ and full technological externalities, the

\footnotetext{
${ }^{24}$ Figure D.2 in the Appendix D.2 shows another remarkable result is that the global trends in international migration are virtually unaffected by the technological environment; they are totally governed by socio-demographic changes.
} 
(a) World GDP per worker

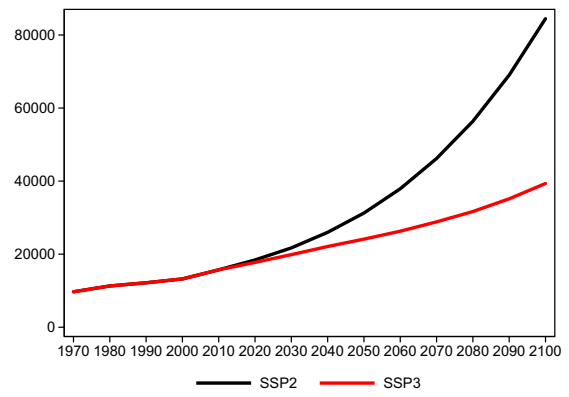

(c) World proportion of migrants

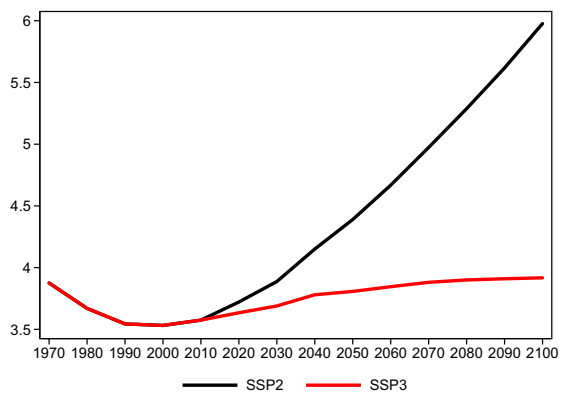

(b) Theil index

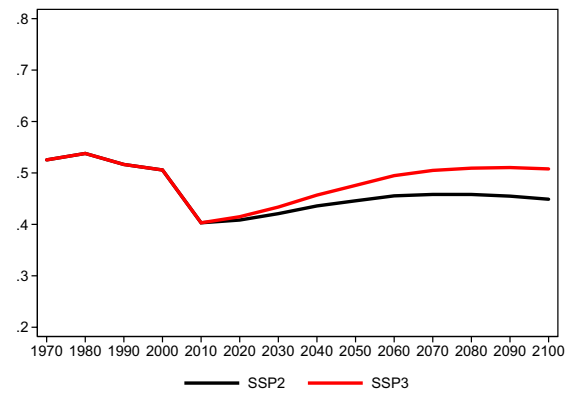

(d) Share of college-educated migrants

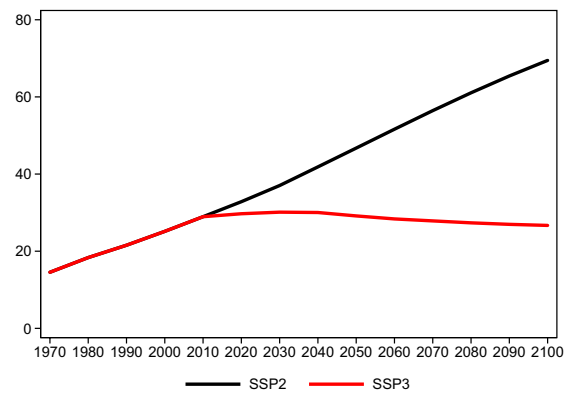

(e) Emigration rates from developing countries (f) Immigration rate to OECD countries
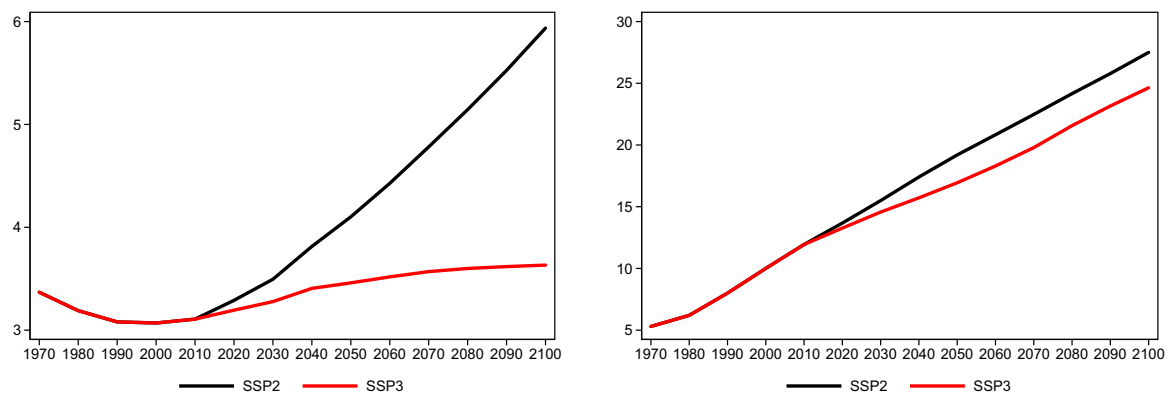

Fig. 4 Global income and migration forecasts, 1970-2100. a World GDP per worker. b Theil index. c World proportion of migrants. d Share of college-educated migrants. e Emigration rates from developing countries. f Immigration rate to OECD countries. Note: Authors' computations based on the variant with $\gamma=0.7, \sigma=2$ and $\kappa=0.214$

scenario that is the most compatible with future educational changes. ${ }^{25}$ Under SSP2, from 2010 to 2050 , the proportion of immigrants increases from $14.5 \%$ to $24.7 \%$ (i.e. 10.2 percentage points) in the EU15 and from $17.7 \%$ to $26.7 \%$ (i.e. 9 percentage points) in the United States. Under SSP2 and over the 21st century, the proportion of

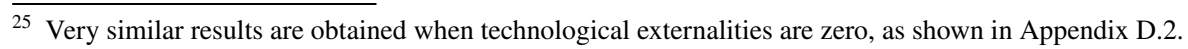


Table 1 Proportion of working-age immigrants by main destination (constant migration costs)

\begin{tabular}{|c|c|c|c|c|c|c|c|c|c|c|c|}
\hline & 2010 & 2020 & 2030 & 2040 & 2050 & 2060 & 2070 & 2080 & 2090 & 2100 & $\Delta$ \\
\hline \multicolumn{12}{|c|}{ SSP2, $\gamma=0.7, \sigma=2$, full technological externalities } \\
\hline EU15 & 14.5 & 16.8 & 19.3 & 22.2 & 24.7 & 26.8 & 29.1 & 31.3 & 33.5 & 36.5 & +21.2 \\
\hline France & 14.7 & 18.0 & 21.0 & 24.0 & 26.2 & 28.2 & 30.3 & 32.4 & 34.4 & 36.5 & +21.8 \\
\hline Germany & 15.9 & 17.3 & 19.3 & 21.3 & 22.0 & 22.8 & 23.7 & 24.0 & 24.3 & 24.9 & +9.0 \\
\hline Italy & 10.5 & 11.8 & 13.1 & 14.8 & 15.9 & 16.3 & 16.9 & 17.6 & 18.1 & 18.7 & +8.2 \\
\hline Spain & 14.9 & 16.8 & 19.2 & 22.0 & 25.2 & 26.6 & 27.6 & 28.9 & 29.5 & 29.9 & +15.0 \\
\hline United Kingdom & 16.5 & 19.9 & 24.2 & 28.8 & 32.8 & 37.2 & 41.1 & 45.1 & 48.9 & 52.3 & +35.9 \\
\hline Switzerland & 31.4 & 33.2 & 35.7 & 38.8 & 40.7 & 42.9 & 45.0 & 46.9 & 48.9 & 51.0 & +19.6 \\
\hline United States & 17.7 & 20.4 & 23.3 & 25.2 & 26.7 & 28.0 & 29.1 & 30.1 & 30.9 & 31.9 & +14.3 \\
\hline Canada & 24.5 & 29.4 & 35.3 & 40.1 & 44.3 & 48.4 & 51.7 & 54.5 & 57.3 & 60.0 & +35.6 \\
\hline Australia & 28.7 & 31.2 & 33.8 & 36.3 & 38.4 & 40.7 & 42.5 & 44.3 & 46.3 & 48.2 & +19.4 \\
\hline OECD & 11.9 & 13.7 & 15.5 & 17.4 & 19.2 & 20.8 & 22.5 & 24.2 & 25.8 & 27.5 & +15.6 \\
\hline \multicolumn{12}{|c|}{ SSP3, $\gamma=0.7, \sigma=2$, full technological externalities } \\
\hline EU15 & 14.5 & 16.4 & 18.4 & 20.7 & 22.8 & 25.3 & 28.2 & 31.9 & 35.4 & 38.9 & +24.3 \\
\hline France & 14.7 & 17.4 & 19.4 & 21.2 & 22.7 & 24.6 & 27.1 & 30.3 & 33.3 & 36.3 & +22.2 \\
\hline Germany & 15.9 & 17.3 & 19.3 & 21.5 & 23.2 & 25.6 & 28.9 & 32.3 & 36.0 & 40.0 & +24.1 \\
\hline Italy & 10.5 & 11.8 & 13.2 & 15.2 & 17.3 & 19.3 & 21.8 & 25.4 & 28.6 & 32.1 & +21.6 \\
\hline Spain & 14.9 & 16.6 & 18.7 & 21.4 & 25.2 & 28.1 & 31.0 & 35.4 & 38.8 & 41.9 & +27.0 \\
\hline United Kingdom & 16.5 & 18.6 & 21.3 & 23.4 & 25.5 & 28.6 & 31.7 & 35.8 & 39.8 & 43.6 & +26.2 \\
\hline Switzerland & 31.4 & 32.5 & 34.1 & 36.1 & 37.3 & 39.3 & 41.5 & 44.1 & 46.9 & 49.7 & +18.4 \\
\hline United States & 17.7 & 19.8 & 22.2 & 23.5 & 25.3 & 27.6 & 30.2 & 33.6 & 36.8 & 40.1 & +22.4 \\
\hline Canada & 24.5 & 27.4 & 31.2 & 33.5 & 35.7 & 39.1 & 42.3 & 46.3 & 50.3 & 54.2 & +29.8 \\
\hline Australia & 28.7 & 29.9 & 31.4 & 32.4 & 33.5 & 35.5 & 37.6 & 40.5 & 43.8 & 47.0 & +18.2 \\
\hline OECD & 11.9 & 13.3 & 14.6 & 15.7 & 16.9 & 18.3 & 19.8 & 21.6 & 23.2 & 24.6 & +12.7 \\
\hline
\end{tabular}

immigrants increases by 21.2 percentage points in the EU15 and by 14.3 percentage points in the United States. The greatest variations are obtained for the United Kingdom and for Canada. Under SSP3, the average population growth rates are larger in developing countries, with the exception of Asia. The proportion of immigrants increases by 8.3 percentage points by 2050 and 24.3 percentage points by 2100 in the EU15, and by 7.6 percentage points by 2050 and 22.4 percentage points by the end of the century in the United States. The greatest variations are obtained for Spain, the United Kingdom and for Canada. Projections for the coming 50 years are farily robust to the socio-demographic scenario, and extremely robust to the technological scenario.

In line with Hanson and McIntosh (2016) or Docquier and Machado (2017), future migration pressures mainly affect European countries, and are mostly due to rising migration flows from developing countries. To illustrate this, we use the same Max-Sum Submatrix algorithm as in the previous section, and apply it to the matrix of total migration net flows from developing countries to the 27 members of the European Union between 2010 and 2060; projections for subsequent years are more 
uncertain and scenario-sensitive. For each socio-demographic scenario, we identify the sub-matrix with a fixed dimension of $25 \times 10$ that maximizes the total migration net flows.

Under the SSP2 scenario, we obtain the following results (in alphabetical order):

- Main destination countries: Belgium, France, Germany, Ireland, Italy, Netherlands, Portugal, Spain, Sweden, and the United Kingdom.

- Main countries of origin: Afghanistan, Algeria, Angola, Bangladesh, Cameroon, Dem. Rep. of Congo, Cote d'Ivoire, Ghana, India, Iran, Iraq, Kenya, Madagascar, Mali, Morocco, Mozambique, Nigeria, Pakistan, Philippines, Senegal, Somalia, Tanzania, Turkey, Uganda, and Zimbabwe.

And under the SSP3 scenario, we have (by alphabetical order):

- Main destination countries: Austria, Belgium, France, Germany, Italy, Netherlands, Portugal, Spain, Sweden, and the United Kingdom.

- Main countries of origin: Afghanistan, Algeria, Angola, Bangladesh, Bolivia, Colombia, Dem. Rep. of Congo, Cote d'Ivoire, Ecuador, Ghana, India, Iraq, Kazakhstan, Kenya, Madagascar, Mali, Morocco, Nigeria, Pakistan, Peru, Philippines, Senegal, Somalia, Turkey, and Uganda.

Under SSP2, migration flows from sub-Saharan Africa and from the MENA play a key role, as well as the flows from a few Asian countries with large populations. As the majority of African migrants go to Europe, the EU15 experience greater migration pressures. Under SSP3, this change is mostly due to immigration from Africa, although the magnitude of this phenomenon is smaller than under SSP2. However, migration pressures from Asia, from MENA, and from some Latin American countries are stronger. Clearly, there is a large intersection of 9 destination countries (see countries in italics above) that are all member states of the EU15, and for which future migration pressures are expected to be strong, whatever the sociodemographic scenario for the coming half century. And there is large intersection of 20 developing countries (in italics above) that are responsible for such migration pressures, including sub-Saharan African countries, the MENA countries, and a few Asian countries.

Remarkably, the predicted rise in immigration to the main destination countries can be accompanied by a major change in its skill structure. Table 2 shows that the share of the highly skilled in the total number of immigrants to the main destination countries has always been increasing since 1970 and will continue to rise over the 21 st century in the SSP2 scenario. By 2050, the share of high skilled will reach 49.7\% in the EU15, 56.4\% in the United States, 90.1\% in Canada, and $68.5 \%$ in Australia. By the end of the century, this number will rise drastically to reach $75.1 \%$ in the EU15, 79.4\% in the United States, 91.9\% in Canada, and 85.2\% in Australia. In other words, under SSP2 the number of immigrants to the main destinations will increase but they will also be more and more skilled. The situation differs with SSP3 where those numbers will sluggish and only increase by 1 or 2 percentage points compared to the current levels of 2010. 


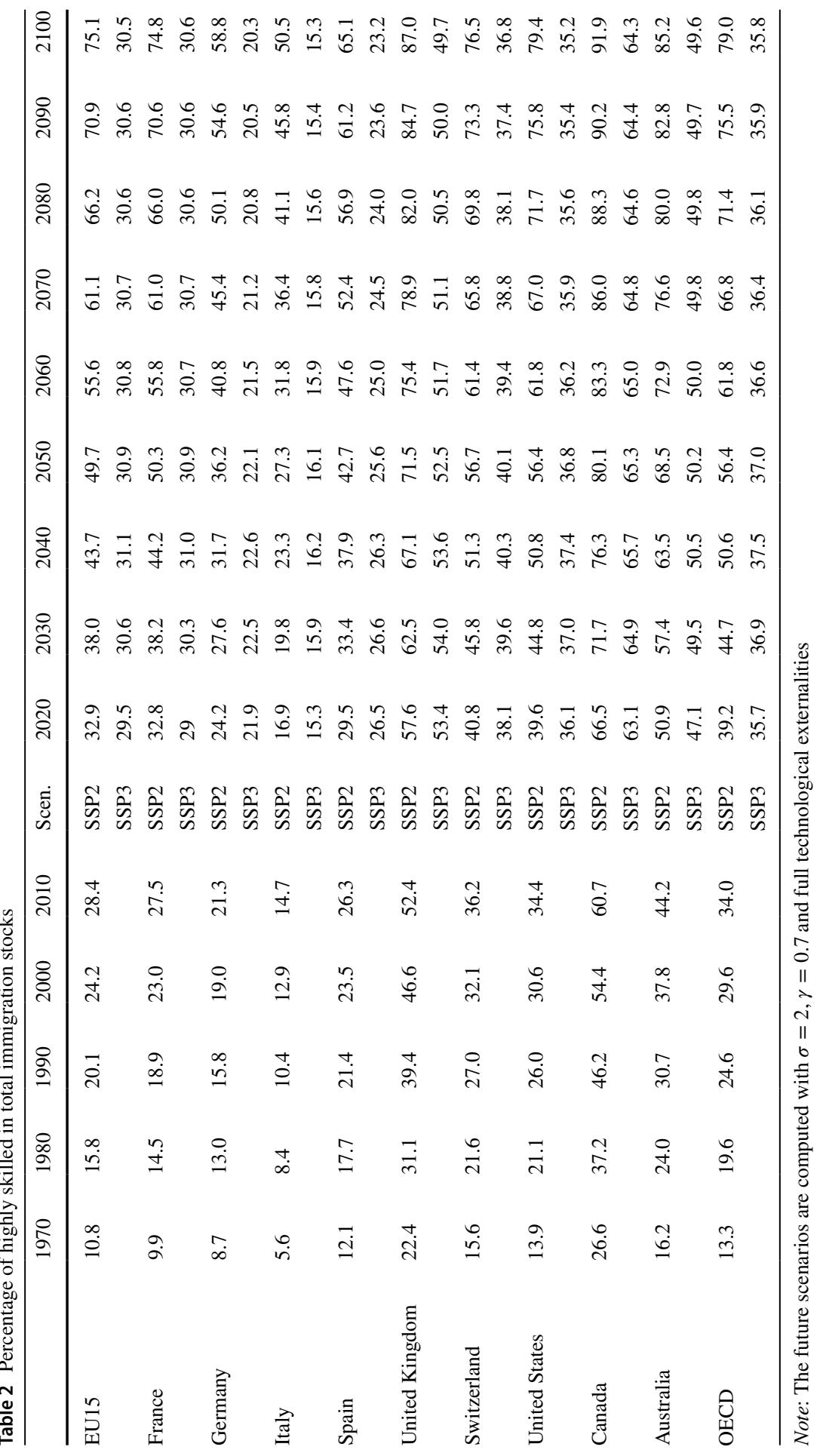


(a) SSP2

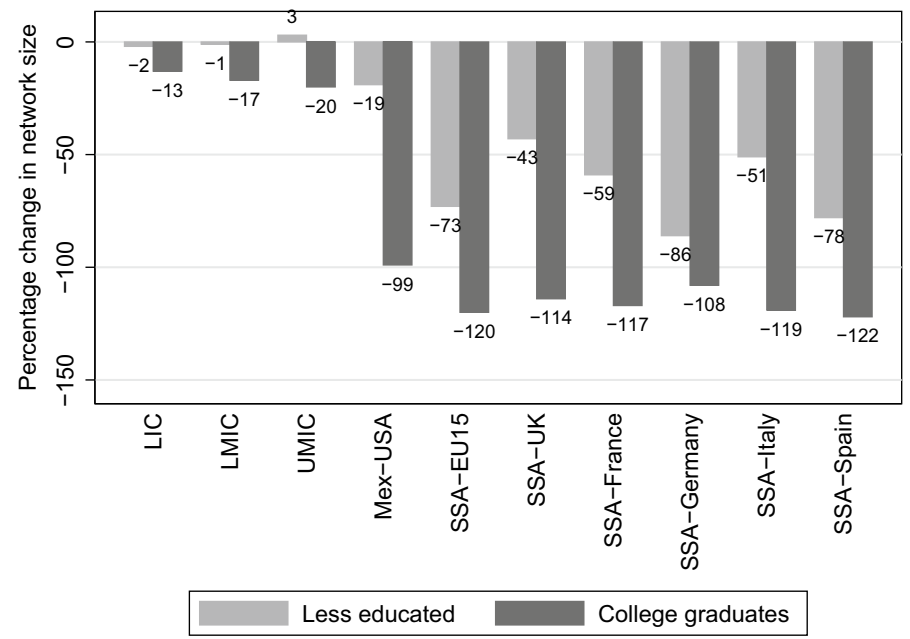

(b) SSP3

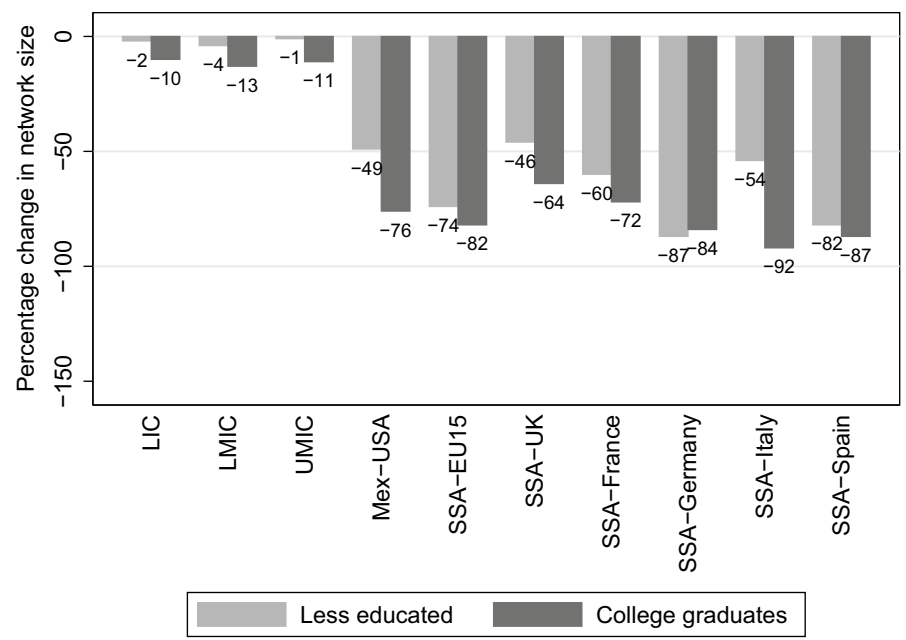

Fig. 5 Migration policies to limit migration pressures (Expressed as equivalent variations in the dyadic network size required to keep skill-specific migration stocks constant) a SSP2. b SSP3. Note: We computed the relative change in the scale factor of the migration technology, $\frac{\Delta V_{i j}}{V_{i j}}$, required to keep bilateral migration stocks constant over the period 2010-2050. We express this change as an equivalent decrease in the network size using $\frac{\Delta V_{i j}}{V_{i j}}=0.725 \times \frac{\Delta \text { Netw }_{i j}}{\text { Netw }_{i j}}$. Results for college graduates (in dark gray) and the the less educated (in light gray) are thus expressed in terms of $\frac{\Delta \text { Netw }_{i j}}{\text { Netw }_{i j}}$

The case for migration restrictions We finally turn our attention to the inescapable nature of these migration trends. To illustrate the difficulty of curbing future migration pressure with immigration restrictions, we computed the relative change in $V_{i j}$ required to keep the dyadic and skill-specific migration stocks at their level 
of 2010 in the years 2020,2030, 2040 and 2050. The scale factor $V_{i j, s}$, while not directly interpretable in monetary unit, is proportional to migration costs which are affected by many factors, among which the size of the dyadic migration stocks is one of its most important determinants identified in the literature. As the elasticity of $V_{i j, s}$ to the network size is equal to 0.725 (see Table A.1 in the Appendix A), dividing the relative change in $V_{i j, s}$ by 0.725 gives the relative change in the network size that is required to limit people's incentives to emigrated and keep the stock of migrants constant. The average result for income groups and for the main migration corridors are depicted in Fig. 5 under the SSP2 scenario.

As SSP2 predicts a rise in human capital, future migration pressures are stronger among college graduates than among the less educated. Hence, keeping skill-specific migration stocks at their level of 2010 requires a drastic change in $V_{i j, h}$, and smaller changes in $V_{i j, l}$. Looking at broad income groups, changes in $V_{i j, h}$ are equivalent to reducing the network size by 13 to $21 \%$. However, looking at the largest migration corridors (Mexico to US and sub-Saharan African countries to the EU15), the fall in $V_{i j, h}$ is usually close to $100 \%$ (and sometimes even higher) while the fall in $V_{i j, l}$ varies between $19 \%$ in the case of Mexican migrants to the US, and $86 \%$ in case of African migrants to Germany. Under SSP3, similare changes in $V_{i j, l}$ and $V_{i j, l}$ are required to keep migration stocks constant. While it is difficult to translate these measures into migration policy variables, our results suggest that sealed borders are virtually needed to control future migration pressures, as it is the case during the current Covid-19 crisis. The target is likely unattainable if the basic right to family reunification is respected.

The case for development policies Under the European Migration Compacts, ${ }^{26}$ an investment plan has also been proposed to stimulate employment opportunities and income in Africa, in the hope of reducing migration pressures. The effectiveness of these Migration Compacts depends on the resources allocated to their implementation (in comparison to the development targets to be reached), and on the effectiveness of the measures undertaken. To illustrate the difficulty curbing future migration pressure with development policies, we consider the intersection of 20 developing countries emerging from our Max-Sum Submatrix problem (referred to as Compact 1), ${ }^{27}$ or the combined region of sub-Saharan African and the MENA countries (referred to as Compact 2). We consider these sets of countries as potential partners of a Migration Compact, and we quantify the homothetic change in TFP (above normal trend) and derive the consequent GDP annual growth rates required

\footnotetext{
${ }^{26}$ In line with the Sustainable Development Goals and the New York Declaration for Refugees and Migrants (UN 2016), the European Commission has outlined a general line of action to address the global challenge of future migration (see the European Agenda on Migration and the new Partnership Framework on Migration). Migration Compacts include a set of measures to be implemented in the home country, targeting the reinforcement of border controls, the readmission of migrants who have been denied entry, or a higher level of economic development.

27 These include Afghanistan, Algeria, Angola, Bangladesh, Dem. Rep. of Congo, Cote d'Ivoire, Ghana, India, Iraq, Kenya, Madagascar, Mali, Morocco, Nigeria, Pakistan, Philippines, Senegal, Somalia, Turkey, and Uganda.
} 
to keep their total emigration stocks to Europe at their levels of 2010. Our simulations account for all general equilibrium effects.

Table 3 provides the results of these policy experiments, taking the population size and structure as given. Our discussion mainly focuses on net migration flows in the next two decades, the period for which socio-demographic variations between SPP2 and SPP3 are smaller and less likely to be affected by the TFP changes. In other words, this consideration partially mitigates the issue that fertility and human capital are endogenously affected by income, which our model does not account for. Indeed, if TFP and GDP start increasing from 2010 onwards, population growth rates and the skill composition of the labor force will be gradually impacted. Results obtained for 2030 and after (essentially beyond one generation) are likely to overestimate the requested changes and should be treated with more caution.

Under the SSP2 socio-demographic scenario, keeping the stock of the 20 main origin countries (Compact 1) at its level of 2010 requires TFP to increase by $58 \%$ in 2020 and by $128 \%$ in 2030 , compared to the baseline. Under the SSP3 scenario, the required TFP changes amount to $49 \%$ in 2020 and by $99 \%$ in 2030 . Overall, this means multiplying GDP per capita by 2 above the normal trend over the next two decades. Equivalently, this requires a TFP growth rate of 5\% per year under SPP2 (instead of $1.5 \%$ a year in the baseline), and a TFP growth rate of $4.2 \%$ a year under SPP3. In terms of GDP growth, the required levels are on average twice as high as the baseline levels; in all variants, the requested annual GDP growth rate is close to $10 \%$. Implementing Migration Compacts with all sub-Saharan African and MENA countries (Compact 2) requires similar changes in TFP and gives rise to similar effects. $^{28}$

Takeoffs of this nature have rarely been observed in the course of history. ${ }^{29}$ They basically require all SSA and MENA countries to enter the "modern growth club" during the 21st century. Based on facts from the 19th and 20th centuries, Bénétrix et al. (2015) estimate that joining the club requires an annual GDP growth rate above $5 \%$ over a period of ten years; Jones and Romer (2010) argue that higher threshold growth rates are needed in the current period. Still, "explosive-growth" episodes were indeed recently observed in emerging countries. Taiwan multiplied its income per capita by 5 between 1980 and 2000, and South Korea multiplied it by 7.5 over the same period; China has increased its income level tenfold since 1990 with an average GDP growth rate of $8 \%$ per year. Similar takeoffs have not been observed in sub-Saharan Africa. However, Rwanda, which is usually seen as one of the fastest growing economies in Africa, has increased its income per capita threefold in the post-genocide period.

\footnotetext{
${ }^{28}$ We have also conducted another set of simulations (Compact 3) keeping constant the total emigration stocks of sub-Saharan African countries only. The resulting required TFP growth rates are higher than the ones in Compact 2 where growth is fostered in both the MENA and SSA regions. This shows the capacity of the MENA countries to absorb migrants from SSA. Thus smaller but simultaneous investment in both regions is recommended to curb migration pressures to Europe.

29 This was even the case during the Industrial Revolution. Between 1820 and 1900, GDP per capita rose 2.5 times in Western Europe, and 3.3 fold in the United States (Maddison 2007). In other words, growth rates were 1.2 and $1.5 \%$ a year, respectively.
} 
Table 3 Development policies to limit migration pressures

\begin{tabular}{|c|c|c|c|c|c|c|c|}
\hline & 2010 & 2020 & 2030 & 2040 & 2050 & 2060 & 2100 \\
\hline & \multicolumn{7}{|c|}{ I. Socio-demographic scenario: SSP2 } \\
\hline Baseline immigration rate to EU15 & 14.6 & 16.8 & 19.3 & 22.2 & 24.7 & 26.8 & 35.8 \\
\hline Compacts 1 & \multicolumn{7}{|c|}{ I.a. 20 main origin countries } \\
\hline TFP change: $A_{j, t} / A_{j, t}^{\text {Base }}$ & 1.00 & 1.58 & 2.28 & 3.19 & 4.18 & 5.24 & 9.73 \\
\hline New immigration rate EU15 & 14.6 & 15.6 & 16.9 & 18.5 & 19.5 & 20.4 & 24.9 \\
\hline Mean annual GDP growth over decade (Base) & & 5.17 & 5.00 & 4.82 & 4.58 & 4.33 & 3.48 \\
\hline Mean annual GDP growth over decade & & 10.28 & 9.59 & 9.11 & 8.54 & 7.99 & 6.25 \\
\hline Compacts 2 & \multicolumn{7}{|c|}{ I.b. All sub-Saharan Africa and MENA } \\
\hline TFP change: $A_{j, t} / A_{j, t}^{\text {Base }}$ & 1.00 & 1.58 & 2.28 & 3.24 & 4.30 & 5.51 & 11.81 \\
\hline New immigration rate EU15 & 14.6 & 15.6 & 16.9 & 18.3 & 19.3 & 20.0 & 22.6 \\
\hline Mean annual GDP growth over decade (Base) & & 5.06 & 4.85 & 4.67 & 4.42 & 4.16 & 3.34 \\
\hline \multirow[t]{2}{*}{ Mean annual GDP growth over decade } & & 10.22 & 9.47 & 9.05 & 8.48 & 7.95 & 6.37 \\
\hline & \multicolumn{7}{|c|}{ II. Socio-demographic scenario: SSP3 } \\
\hline Baseline immigration rate to EU15 & 14.6 & 16.4 & 18.4 & 20.7 & 22.8 & 25.3 & 38.9 \\
\hline Compacts 1 & \multicolumn{7}{|c|}{ II.a. 20 main origin countries } \\
\hline TFP change: $A_{j, t} / A_{j, t}^{\text {Base }}$ & 1.00 & 1.49 & 1.99 & 2.51 & 3.06 & 3.67 & 6.40 \\
\hline New immigration rate EU15 & 14.6 & 15.4 & 16.5 & 17.7 & 18.8 & 20.1 & 28.1 \\
\hline Mean annual GDP growth over decade (Base) & & 4.54 & 4.36 & 4.17 & 4.01 & 3.86 & 3.3 \\
\hline Mean annual GDP growth over decade & & 8.95 & 8.15 & 7.53 & 7.05 & 6.68 & 5.51 \\
\hline Compacts 2 & \multicolumn{7}{|c|}{ II.b. All sub-Saharan Africa and MENA } \\
\hline TFP change: $A_{j, t} / A_{j, t}^{\text {Base }}$ & 1.00 & 1.49 & 1.97 & 2.48 & 2.99 & 3.54 & 5.89 \\
\hline New immigration rate EU15 & 14.6 & 15.4 & 16.5 & 17.7 & 18.8 & 20.2 & 28.8 \\
\hline Mean annual GDP growth over decade (Base) & & 4.51 & 4.25 & 4.05 & 3.85 & 3.67 & 3.1 \\
\hline Mean annual GDP growth over decade & & 8.95 & 8 & 7.38 & 6.84 & 6.42 & 5.22 \\
\hline
\end{tabular}

Sustaining TFP growth rates of 4 to $5 \%$ or real GDP growth rates of 8 to $10 \%$ per year on the spatial scale of a continent and over several decades is unprecedented. So far, development policies have not triggered such resounding and generalized economic booms (Hausmann et al. 2005). Hence, dramatic changes in the effectiveness of aid are needed if policymakers want to use development tools to reduce migration pressures (Berthélemy et al. 2009; Berthélemy and Maurel 2010; Gary and Maurel 2015). In addition, generating these booms in SSA and MENA would only attenuate migration pressures to Europe, but would not eliminate them since migration pressures from other countries and regions would still be observed. Table 3 shows that the EU15 immigration rate in 2060 would be around $20 \%$ in all scenarios, compared to $14.6 \%$ in 2010 . Reinforcing immigration restrictions is another complementary policy avenue. However, it is a priori unclear whether changes in laws and policies can significantly affect the size of immigration flows. Past restrictions on migration have not prevented third-country nationals from moving in past decades (it may be recalled that our backcasts 
with constant $V_{i j, s, t}$ fit well past migration flows), and have caused displacements and increasing flows of irregular migrants. Over the 21 st century, increasing migration seems to be an inevitable phenomenon, which raises important challenges in terms of policy coherence for most industrialized countries.

\section{Conclusion}

The number of asylum applications lodged in 2015 in EU Member States exceeded 1.3 million, putting migration policy in the forefront of the global policy debate. While the proximate cause of the current crisis is the conflict and political unrest in the Middle East and Africa, the recent trends and forecasts for the world economy strongly suggest that there may be further episodes of large-scale migration in the near future, in Europe and in other OECD countries. Specifically, the underlying root causes of increased migration (demographic growth differentials, economic inequality, increased globalization, political instability, climatic changes) are all projected to exert a stronger influence on migration in the coming decades.

Relying on socio-demographic and technological scenarios, this paper produces integrated backcasts, nowcasts and forecasts of income and bilateral migration stocks for all pairs of countries. Our model fits very well the trends in international migration of the last 40 years, and demonstrates that historical trends were mostly governed by demographic changes. Turning to the migration prospects for the $21 \mathrm{st}$ century, we also find that world migration prospects are mainly governed by sociodemographic changes; they are virtually insensitive to the technological environment. We predict a highly robust increase in immigration pressures in general, and in European immigration in particular. These migration pressures are mostly explained by the demographic changes in sub-Saharan Africa and in the MENA countries. Curbing them with immigration restrictions or with development policies requires sealing borders or triggering unprecedented economic booms in many developing countries. More than ever, improving the management of migration flows and the coherence between development and migration policies will represent major challenges for European countries in the 21st century. In particular, helping developing countries to increase human capital for all and for women in particular could drastically transform the skill structure of global migration and make destination countries less hostile to immigrants.

\section{References}

Acemoglu, D. (2002). Technical change, inequality, and the labor market. Journal of Economic Literature, 40(1), 7-72.

Acemoglu, D., \& Angrist, J. (2000). How large are human-capital externalities? Evidence from compulsory schooling laws. NBER Macroeconomics Annual, 15, 9-59.

Angrist, J. (1995). The economic returns to schooling in the West Bank and Gaza strip. American Economic Review, 6(1), 1065-1087. 
Arslan, C., Dumont, J., Kone, Z., Moullan, Y., Ozden, C., Parsons, C., \& Xenogiani, T. (2015). A new profile of migrants in the aftermath of the recent economic crisis. (OECD Social, Employment and Migration Working Papers), 160. https://www.oecd.org/els/mig/wp160.pdf

Autor, D., Levy, F., \& Murnane, R. (2003). The skill content of recent technological change: An empirical exploration. Quarterly Journal of Economics, 118(4), 1279-1333.

Beine, A., Bourgeon, P., \& Bricongne, J. (2019). Aggregate fluctuations and international migration. Scandinavian Journal of Economics, 121(1), 117-152.

Beine, M., \& Parsons, C. (2015). Climatic factors as determinants of international migration. Scandinavian Journal of Economics, 117(2), 723-767.

Bénétrix, A., O-Rourke, K., \& Williamson, J. (2015). The spread of manufacturing to the poor periphery 1870-2007. Open Economies Review, 26(1), 1-37.

Benhabib, J., \& Spiegel, M. (1994). The role of human capital in economic development evidence from aggregate cross-country data. Journal of Monetary Economics, 34(2), 143-173.

Berthélemy, J., Beuran, M., \& Maurel, M. (2009). Aid and migration: Substitutes or complements? World Development, 37(10), 1589-1599.

Berthélemy, J. \& Maurel, M. (2010). The consistency of EU foreign policies towards new member states. In: Keereman F., Szekely I. (eds) Five Years of an Enlarged EU. Springer, Berlin, Heidelberg.

Bertoli, S., \& Moraga Fernandez-Huertas, J. (2013). Multilateral resistance to migration. Journal of Development Economics, 102, 79-100.

Bertoli, S., \& Moraga Fernandez-Huertas, J. (2015). The size of the cliff at the border. Regional Science and Urban Economics, 51(C), 1-6.

Bobba, M., \& Coviello, D. (2007). Weak instruments and weak identification, in estimating the effects of education, on democracy. Economic Letters, 96(3), 301-306.

Bolt, J., \& Van Zanden, J. (2014). The maddison project: Collaborative research on historical national accounts. Economic History Review, 67(3), 627-651.

Borjas, G. (2003). The labor demand curve is downward sloping: Reexamining the impact of immigration on the labor market. Quarterly Journal of Economics, 118(4), 1335-1374.

Borjas, G. (2013). The analytics of the wage effect of immigration. IZA Journal of Migration, 2(1), 22.

Burzynski, M., Deuster, C., Docquier, F., \& de Melo, J. (2019). Climate change, inequality and human migration. (CEPR Discussion Paper), No. 13997, CEPR: London.

Card, D. (2009). Immigration and inequality. American Economic Review, 99(2), 1-21.

Card, D., \& Lemieux, T. (2001). Can falling supply explain the rising return to college for younger men? A cohort-based analysis. Quarterly Journal of Economics, 116(2), 705-746.

Caselli, F., Coleman, I., \& John, W. (2006). The world technology frontier. American Economic Review, 96(3), 499-522.

Castelló-Climent, A. (2008). On the distribution of education and democracy. Journal of Development Economics, 87(2), 179-190.

Ciccone, A., \& Papaioannou, E. (2009). Human capital, the structure of production, and growth. Review of Economics and Statistics, 91(1), 66-82.

Clark, X., Hatton, T., \& Williamson, J. (2007). Explaining us immigration, 1971-1998. Review of Economics and Statistics, 89(2), 359-373.

Desmet, K., Kopp, R., Kulp, S., Nagy, D., Oppenheimer, M., Rossi-Hansberg, E., \& Strauss, B. (2018). Evaluating the economic cost of coastal flooding. (NBER Working Paper), No. 24918, NBER: Cambridge, MA.

Djajic, S., Kirdar, M., \& Vinogradova, A. (2016). Source-country earnings and emigration. Journal of International Economics, 99, 46-67.

Docquier, F., \& Machado, J. (2017). Income disparities, population and migration flows over the twenty first century. Italian Economic Journal, 3(2), 125-149.

Docquier, F., Machado, J., \& Sekkat, K. (2015). Efficiency gains from liberalizing labor mobility. Scandinavian Journal of Economics, 117(2), 303-346.

Gary, A., \& Maurel, M. (2015). Donors' policy consistency and economic growth. Kyklos, 68(4), 511-551.

Grogger, J., \& Hanson, G. (2011). Income maximization and the selection and sorting of international migrants. Journal of Development Economics, 95(1), 42-57.

Hanson, G., \& McIntosh, C. (2016). Is the mediterranean the new Rio Grande? US and EU immigration pressures in the long run. Journal of Economic Perspectives, 30(4), 57-82.

Hatton, T., \& Williamson, J. (1998). The age of mass migration: Causes and economic impact. Oxford: Oxford University Press. 
Hatton, T., \& Williamson, J. (2003). Demographic and economic pressure on emigration out of Africa. Scandinavian Journal of Economics, 105(3), 465-486.

Hatton, T., \& Williamson, J. (2011). Are third world emigration forces abating? World Development, 39(1), 20-32.

Hausmann, R., Pritchett, L., \& Rodrik, D. (2005). Growth accelerations. Journal of Economic Growth, 10(4), 303-329.

Hendricks, L. (2004). A database of mincerian earnings regressions. Available online at,. www.lhend ircks.org/Mincer.htm.

Iranzo, S., \& Peri, G. (2009). "Schooling externalities, technology, and productivity: Theory and evidence from U.S. states. Review of Economics and Statistics, 91(2), 420-431.

Jones, C., \& Romer, P. (2010). The new Kaldor facts: ideas, institutions, population, and human capital. American Economic Journal: Macroeconomics, 2(1), 224-245.

Katz, L., \& Murphy, K. (1992). Changes in relative wages, 1963-1987: Supply and demand factors. Quarterly Journal of Economics, 107(1), 35-78.

Kennan, J. (2013). Open borders. Review of Economic Dynamics, 16(2L), 1-13.

Klein, P., \& Ventura, G. (2009). Productivity differences and the dynamic effects of labor movements. Journal of Monetary Economics, 56(8), 1059-1073.

Krzywinski, M., Schein, J., Birol, I., Connors, J., Gascoyne, R., Horsman, D., et al. (2009). Genome Research, 19, 1639-1645.

Lucas, J. R. (1988). On the mechanics of economic development. Journal of Monetary Economics, 22(1), $3-42$.

Lutz, W., Butz, W., \& Samir, K. (2017). World Population and Human Capital in the Twenty-First Century: An Overview. Oxford: Oxford University Press.

Maddison, A. (2007). Contours of the world economy 1-2030 AD: Essays in macro-economic history. Oxford: Oxford University Press.

Maurel, M., \& Tuccio, M. (2015). Climate instability, urbanization and international migration. Journal of Development Studies, 52(5), 735-752.

McFadden, D. (1984). Econometric analysis of qualitative response models. Handbook of Econometrics, $2,1395-1457$.

Missirian, A., \& Schlenker, W. (2014). Asylum applications respond to temperature fluctuations. Science, 358(6370), 1610-1614.

Moretti, E. (2004). Workers' education, spillovers, and productivity: Evidence from plant-level production functions. American Economic Review, 94(3), 656-690.

Murtin, F., \& Wacziarg, R. (2014). The democratic transition. Journal of Economic Growth, 19(2), 141-181.

Ortega, F., \& Peri, G. (2009). The causes and effects of international migrations: Evidence from OECD countries 1980-2005. (NBER Working Paper), No. 14833, NBER: Cambridge, MA.

Ortega, F., \& Peri, G. (2013). The role of income and immigration policies in attracting international migrants. Migration Studies, 1(1), 1-28.

Ottaviano, G., \& Peri, G. (2012). Rethinking the effect of immigration on wages. Journal of the European Economic Association, 10(1), 152-197.

Ozden, C., Parsons, C., Schiff, M., \& Walmsley, T. (2011). Where on earth is everybody? The evolution of global bilateral migration 1960-2000. World Bank Economic Review, 25(1), 12-56.

Restuccia, D., \& Vandenbroucke, G. (2013). The evolution of education: A macroeconomic analysis. International Economic Review, 54(3), 915-936.

Rigaud, K. K., de Sherbinin, A., Jones, B., Bergmann, J., Clement, V., Ober, K., Schewe, J., Adamo, S., McCusker, B., Heuser, S., et al. (2018). Groundswell - preparing for internal climate migration.

UN, G. A. (2016). New York declaration for refugees and migrants. United Nations, Doc. A/71/L, 1, 13, United Nations: New York.

UNDESA (2013). World Youth Report: Youth and Migration. United Nations: New York.

Publisher's Note Springer Nature remains neutral with regard to jurisdictional claims in published maps and institutional affiliations. 


\section{Affiliations}

\section{Thu Hien Dao ${ }^{1,2} \cdot$ Frédéric Docquier $^{3} \cdot$ Mathilde Maurel $^{4,5,6} \cdot$ Pierre Schaus $^{7}$}

$\triangle$ Thu Hien Dao

daothuhien.dth@gmail.com

Frédéric Docquier

frederic.docquier@liser.lu

Mathilde Maurel

mathilde.maurel@univ-paris1.fr

Pierre Schaus

pierre.schaus@uclouvain.be

1 RES/LIDAM, Université catholique de Louvain, Louvain-la-Neuve, Belgium

2 Department of Economics, University of Bielefeld, Bielefeld, Germany

3 LISER, Esch-sur-Alzette, Luxembourg

4 Centre d'Économie de la Sorbonne (CES - UMR8174), Université Paris 1 Panthéon-Sorbonne, Paris, France

5 CNRS, Paris, France

6 FERDI, Clermont-Ferrand, France

7 Department of Computer Science \& Engineering, Université catholique de Louvain, Louvain-la-Neuve, Belgium 